


\section{Governo Federal \\ Ministério da Economia \\ Ministro Paulo Guedes}

\section{- Instituto de Pesquisa Econômica Aplicada}

Fundação pública vinculada ao Ministério da Economia, o Ipea fornece suporte técnico e institucional às ações governamentais - possibilitando a formulação de inúmeras políticas públicas e programas de desenvolvimento brasileiros - e disponibiliza, para a sociedade, pesquisas e estudos realizados por seus técnicos.

\section{Presidente}

Carlos von Doellinger

Diretor de Desenvolvimento Institucional

Manoel Rodrigues Junior

Diretora de Estudos e Políticas do Estado, das Instituições e da Democracia

Flávia de Holanda Schmidt

Diretor de Estudos e Políticas

Macroeconômicas

José Ronaldo de Castro Souza Júnior

Diretor de Estudos e Políticas Regionais, Urbanas e Ambientais

Nilo Luiz Saccaro Júnior

Diretor de Estudos e Políticas Setoriais de Inovação e Infraestrutura

André Tortato Rauen

Diretora de Estudos e Políticas Sociais

Lenita Maria Turchi

Diretor de Estudos e Relações Econômicas

e Políticas Internacionais

Ivan Tiago Machado Oliveira

Assessor-chefe de Imprensa e Comunicação André Reis Diniz

Ouvidoria: http://www.ipea.gov.br/ouvidoria URL: http://www.ipea.gov.br

\section{RADAR}

\section{Tecnologia, produção e comércio exterior}

\author{
Editor responsável
}

Rafael Leão

Radar : tecnologia, produção e comércio exterior / Instituto de Pesquisa Econômica Aplicada. Diretoria de Estudos e Políticas Setoriais de Inovação e Infraestrutura (Diset). - n. 1 (abr. 2009) - . - Brasilia : Ipea, 2009-

Quadrimestral

ISSN: 2177-1855

1. Tecnologia. 2. Produção. 3. Comércio Exterior. 4. Periódicos. I. Instituto de Pesquisa Econômica Aplicada. Diretoria de Estudos e Políticas Setoriais de Inovação e Infraestrutura (Diset).

CDD 338.005

(C) Instituto de Pesquisa Econômica Aplicada - ipea 2021

DOI: http://dx.doi.org/10.38116/radar65

As publicações do Ipea estão disponíveis para download gratuito nos formatos PDF (todas) e EPUB (livros e periódicos). Acesse: http://www.ipea.gov.br/portal/publicacoes

As opiniões emitidas nesta publicação são de exclusiva e inteira responsabilidade dos autores, não exprimindo, necessariamente, o ponto de vista do Instituto de Pesquisa Econômica Aplicada ou do Ministério da Economia.

É permitida a reprodução deste texto e dos dados nele contidos, desde que citada a fonte. Reproduções para fins comerciais são proibidas. 


\section{SUMÁRIO}

IMPACTOS DAS ENERGIAS SOLAR E EÓLICA NA DEMANDA DE BATERIAS DE LÍTIO

José Mauro de Morais

O IMPACTO DAS NOVAS TECNOLOGIAS

NA DEMANDA DO LÍTIO

Eduardo Vale

O IMPACTO DAS NOVAS TECNOLOGIAS

NA DEMANDA DA GRAFITA

17

Eduardo Vale

EVOLUÇÃO RECENTE DO MARKET SHARE

DAS EXPORTAÇÕES MINERAIS BRASILEIRAS

23

Daniel Monte Cardoso

IMPACTO DA COVID-19 NAS EXPORTAÇÕES

DAS PRINCIPAIS COMMODITIES BRASILEIRAS

29

José Aroudo Mota

CONTRIBUIÇÃO DO SETOR MINERAL

NO PRODUTO INTERNO BRUTO BRASILEIRO

33

Rodrigo César de Vasconcelos dos Santos

IMPACTOS DAS MUDANÇAS NA POLÍTICA

NORTE-AMERICANA PARA O SETOR MINERAL BRASILEIRO

Rodrigo César de Vasconcelos dos Santos

Daniel Monte Cardoso 



\section{APRESENTAÇÃO' ${ }^{1}$}

A edição no 65 do boletim Radar, a primeira de 2021, é uma edição especial dedicada ao tema da mineração. Em dezembro de 2019, o Ipea firmou uma parceria institucional com o Ministério de Minas e Energia (MME) para produzir análises e estudos sobre a oferta e demanda do setor mineral e suas potencialidades econômicas e tecnológicas. Até o momento, foram produzidos e entregues ao MME mais de uma dezena de trabalhos úteis ao esforço de elaboração e implementação de políticas públicas. Alguns desses estudos compóem esta edição especial.

Os três primeiros textos são dedicados ao impacto que as novas tecnologias industriais e de geração de energia renovável têm sobre a cadeia produtiva da mineração. O primeiro, Impactos das energias solar e eólica na demanda de baterias de lítio, de José Mauro de Morais, analisa como características específicas dos sistemas de geração eólico e solar, no Brasil, impulsionarão a demanda por baterias de lítio ao longo dos próximos anos.

Ainda tratando do mineral lítio, o segundo texto, O impacto das novas tecnologias na demanda do lítio, de Eduardo Vale, apresenta um diagnóstico horizontal do impacto das novas tecnologias na demanda do lítio. $\mathrm{O}$ texto discute cenários prospectivos direcionados à cadeia industrial do metal. Também de autoria de Eduardo Vale, o terceiro texto, O impacto das novas tecnologias na demanda da grafita, vai na mesma linha, apresentando um diagnóstico atual e analisando cenários futuros da produção da grafita e seus usos industriais.

Os dois textos seguintes tratam do comércio exterior brasileiro no setor da mineração. De autoria de Daniel Monte Cardoso, o texto Evolução recente do market share das exportaçóes minerais brasileiras analisa a competitividade dos principais produtos de exportação mineral brasileiros entre 2015 e 2019, enfatizando a organização geográfica dos maiores centros produtores nacionais. Em uma perspectiva mais conjuntural, o texto Impacto da Covid-19 nas exportaçóes das principais commodities brasileiras, de José Aroudo Mota, analisa o comportamento do comércio exterior brasileiro no período de 2019 a 2020, enfatizando as principais commodities exportadas pelo país.

No sexto estudo, Contribuição do setor mineral no produto interno bruto brasileiro, Rodrigo César de Vasconcelos dos Santos utiliza o Sistema de Contas Nacionais do Instituto Brasileiro de Geografia e Estatística (IBGE) para estimar o produto interno bruto (PIB) do setor mineral brasileiro de 2000 a 2020. É empregada uma abordagem que desconsidera atividades de extração de óleo e gás e inclui setores da indústria de transformação intimamente ligados à extração mineral.

O último texto, escrito por Rodrigo César de Vasconcelos dos Santos e Daniel Monte Cardoso, analisa possíveis impactos das mudanças na política norte-americana sobre o setor mineral brasileiro. Impactos das mudanças na politica norte-americana para o setor mineral brasileiro mostra que as sinalizaçóes em direção a uma matriz energética mais limpa poderiam impactar positivamente o setor mineral brasileiro devido a consideráveis reservas de minerais primordiais para a confecção de baterias e painéis solares, por exemplo.

Rafael Leão

Especialista em políticas públicas e gestão governamental na Diretoria de Estudos e Políticas Setoriais de Inovaçáo e Infraestrutura (Diset) do Ipea e editor deste Radar

1. DOI: http://dx.doi.org/10.38116/radar65apresentacao 



\section{IMPACTOS DAS ENERGIAS SOLAR E EÓLICA NA DEMANDA DE BATERIAS DE LÍTIO'}

José Mauro de Morais²

\section{SINOPSE}

O principal uso de baterias de lítio nos sistemas de energia renovável ocorre nos sistemas solares off grid, e a demanda por essas baterias é impulsionada por fatores como instalaçóes de sistemas em localidades não alcançadas por redes de eletricidade, substituição de baterias de chumbo e a necessidade de estabilização da rede por baterias para corrigir oscilaçóes e interrupçóes de energia. A maior parte da demanda nacional por baterias de lítio é suprida por importaçóes, havendo apenas um pequeno fabricante nacional. As projeçóes de expansão da produção de energia solar no Brasil indicam um caminho de expansão crescente dessa demanda ao longo das próximas décadas.

Palavras-chave: bateria de lítio; baterias; off grid; geração distribuída.

O uso de baterias de lítio nos sistemas de energia renovável ocorre basicamente nos sistemas solares off grid, uma vez que os grandes sistemas de geração solar centralizada e os sistemas de micro e minigeraçáo distribuída on grid ligam-se diretamente à rede de energia elétrica, que funciona como bateria para esses sistemas. Os sistemas on grid não representam, portanto, mercado significativo para baterias de lítio, pelo menos no presente.

A energia eólica, por sua vez, é caracterizada por grandes sistemas de geração ligados às redes elétricas, e não utiliza baterias. Os sistemas menores de geração distribuída (GD) eólica podem necessitar de bateria, porém têm participação ínfima $(0,1 \%)$ na geração eólica como um todo, não impactando a demanda por baterias.

A demanda por baterias de lítio nos sistemas solares off grid é impulsionada por fatores como:

- instalações de sistemas em localidades não alcançadas por redes de eletricidade, em que é alto o custo de conexão à rede e em regióes isoladas;

- propriedades agrícolas ou pontos de propriedades agrícolas sem rede;

- substituição de baterias de chumbo; características da oferta de energia elétrica no país, com a necessidade de estabilização da rede por baterias para corrigir oscilaçóes, ou interrupçóes de energia em períodos de tempo mais longos; e

- situações em que é necessária independência em relação à rede elétrica por questôes de segurança no fornecimento.

Também se espera que, no médio prazo, com redução significativa do preço das baterias de lítio, poderá ocorrer a substituição de motores a diesel, hoje muito utilizados por consumidores atendidos em alta tensão com alto fator de carga na ponta para evitar o consumo e a alta tarifa em horários de ponta (EPE, 2020).

Consultas que realizamos ao mercado revendedor de baterias de lítio para os sistemas solares confirmaram as utilizaçóes acima. Foram contatadas as empresas Solius Solar, Unipower e Aldo Solar, que importam baterias para a comercialização no mercado, especialmente da China, pois a oferta de baterias nacionais é muito pequena. A parcela maior do mercado comprador é representada por sistemas off grid equivalentes à microgeração distribuída (potência instalada até $75 \mathrm{~kW}$ ) e à minigeração distribuída (centrais geradoras com potência acima de $75 \mathrm{~kW}$ até $5 \mathrm{MW}$ ). 
Como única fabricante foi identificada a empresa de pequeno porte Energy Source, localizada no interior do estado de São Paulo, que fabrica baterias com o aproveitamento de baterias antigas por meio de reciclagem. A empresa nos informou que o mercado está aquecido e que vende toda a sua produção, relatando ainda que existe demanda reprimida por conta das dificuldades de importação ocorridas no início da pandemia da Covid-19. Os sistemas off grid respondem por mais de $90 \%$ de suas vendas. Suas baterias recicladas têm menor capacidade e custam um terço da bateria nova.

Segundo nos informou a Energy Source, as baterias de chumbo estão sendo substituídas por baterias de lítio por conta da maior durabilidade e por questóes ambientais, pois as de lítio emitem menos gases poluentes. Por conta do mercado em alta, o fabricante começará a importar células de lítio da China para a fabricação de baterias novas. As células têm posição "ex" na tarifa aduaneira, sem imposto de importação.

Os sistemas on grid atuais raramente adicionam baterias aos equipamentos solares, pois, como foi dito, dispóem da rede para suprir a energia necessária fora do período da incidência solar. No entanto, com a esperada diminuição futura dos atuais subsídios, por meio da cobrança na GD de tarifas que hoje são cobradas na conta de luz dos consumidores sem sistema de energia solar, haverá estímulos para se adicionarem baterias aos sistemas de GD com o objetivo de se armazenar o excedente gerado durante o dia. A adesão à aquisição de baterias dependerá da redução nos preços. Os usuários de sistemas GD que seriam alcançados pela nova legislação poderiam instalar baterias de lítio para armazenar a energia excedente diária, já que, injetando menor quantidade de energia na rede, teriam menos encargos a recolher na energia recebida como crédito da distribuidora de energia.

No mercado internacional, a procura de baterias de lítio para uso em sistemas de geração de eletricidade e em veículos elétricos encontra-se em expansão. Estima-se a queda acentuada nos preços e o aumento da densidade energética das células de lítio em quase 200\%. Esses resultados estão incentivando nos países desenvolvidos, ainda que timidamente, o armazenamento de energia por consumidores residenciais e comerciais ligados a redes de distribuição de energia. Espera-se também a queda acentuada nos preços das baterias de lítio na década que se inicia, havendo estimativa de redução de 8\% ao ano nos preços (BloombergNEF, 2020 apud EPE, 2020). Somente com essa queda esperada nos preços ficaria viável o uso mais comum de baterias nos sistemas on grid.

Não obstante o potencial de expansão dos sistemas solares off grid, e consequentemente da demanda por baterias de lítio, não é possível realizar projeção da capacidade instalada para os próximos anos, como é realizado para a capacidade on grid, pois como a instalação dos sistemas off grid não é alcançada pelo marco legal do sistema de compensação de energia elétrica, isto é, a GD, o Brasil não dispóe de dados estatísticos sobre a capacidade instalada e a evolução recente da energia solar off grid. Consultamos a associação representativa da cadeia produtiva de energia solar, a Associação Brasileira de Energia Solar Fotovoltaica (Absolar), que nos respondeu não dispor de projeçôes de aumento da capacidade instalada de geração de energia solar, on grid e off grid, para os próximos anos.

Para os sistemas de GD on grid, a Empresa de Pesquisa Energética (EPE) realizou projeçóes recentes de expansão da capacidade instalada, como mostra a tabela 1 .

TABELA 1

Evolução da capacidade instalada de geração solar fotovoltaica no Brasil e projeções da EPE para a GD

\begin{tabular}{lrrrr}
\hline \multicolumn{1}{c}{ Solar fotovoltaica } & Dez. 2016 & Dez. 2018 & Out. 2020 & 2025 \\
\hline Geração centralizada (MW) & 24 & 1.798 & 3.114 & - \\
GD (MW) & 57 & 498 & 4.2001 & 10.100 \\
Total solar (MW) & 81 & 2.296 & 7.314 \\
Capacidade total do Brasil - todas as fontes de energia (MW) & 150.410 & 163.441 & 177.671 \\
Energia solar no total do Brasil (\%) & 0,0 & 1,4 & 4,1 \\
\hline
\end{tabular}

Fontes: Brasil (2020) e EPE (2020).

Nota: ${ }^{1}$ Estimativa da EPE. 
A capacidade de geração solar tem crescido de forma exponencial nos últimos anos. A geração centralizada evoluiu $73 \%$ de dezembro de 2018 a outubro de 2020 . Na GD, a taxa de crescimento foi de $740 \%$ de dezembro de 2018 a dezembro de 2020. Em 2019, o acréscimo de potência da GD solar foi maior que a geração eólica (1.400 MW e 900 MW, respectivamente). Para 2025 e 2030, a EPE realizou projeçóes sob duas condiçóes: com a retirada de parte dos subsídios atuais e com a manutenção dos subsídios. As projeçôes variam amplamente de acordo com a manutenção ou não dos subsídios, sendo a projeção da capacidade instalada, em média, 100\% maior se mantidos os subsídios. Para este artigo adotamos as projeçôes menores, sob condição de retirada de parte dos subsídios. Assim, a GD aumenta sua capacidade instalada em 140\% entre 2020 e 2025, e em 300\% entre 2020 e 2030. Essas projeçóes parecem-nos bastante conservadoras diante do crescimento observado nos últimos dois anos $(740 \%)$.

No caso da energia eólica, a Associação Brasileira de Energia Eólica (ABEEólica) projeta que a capacidade instalada dos parques eólicos passará dos atuais 17 mil MW, em 2020, para 27 mil MW, em 2024, ou seja, crescimento de cerca de 60\%. A estimativa foi realizada com os dados dos contratos nos leilóes de energia realizados pela Agência Nacional de Energia Elétrica (Aneel) e do mercado livre, mas, como foi dito, não há uso significativo de baterias nos parques eólicos.

$\mathrm{Na}$ impossibilidade de se realizarem projeçóes sobre a evolução futura da capacidade instalada de sistemas solares off grid, podemos adotar a hipótese de que a procura por essa modalidade de sistema de energia solar apresentará taxas de crescimento em níveis acima das projeçôes realizadas pela EPE para a GD on grid. Essa posiçáo deriva do fato de que, além dos fatores elencados no início deste artigo, que estimulam a demanda por baterias de lítio para sistemas off grid, um fator adicional que poderá ter impacto significativo é a implementação do programa Mais Luz para a Amazônia. Foi estimado recentemente que ainda permanecem sem atendimento de energia elétrica mais de 70 mil famílias na Amazônia Legal, que constituem comunidades isoladas, as quais, pela distância de onde se localizam, não podem ser atendidas pelo sistema convencional das linhas de transmissão das empresas concessionárias. No atendimento àquele número de famílias devem ser adicionadas as atividades econômicas e sociais que com elas coexistem nas pequenas comunidades e que devem ser abastecidas com energia solar, como escolas, igrejas, pequenas manufaturas, resfriamento de alimentos para estocagem, postos de saúde etc.

Em síntese, pode-se adotar como referência mínima para a expansão dos sistemas solares off grid as estimativas realizadas pela EPE para a GD, isto é, $140 \%$ entre 2020 e 2025, e 300\% entre 2020 e 2030, mas com perspectivas de serem maiores, tendo em vista as conservadoras projeçóes da EPE e a implementação do programa Mais Luz para a Amazônia.

\section{REFERÊNCIAS}

BRASIL. Resolução Normativa Aneel no 482, de 17 de abril de 2012. Estabelece as condiçóes gerais para o acesso de microgeração e minigeração distribuída aos sistemas de distribuição de energia elétrica, o sistema de compensação de energia elétrica, e dá outras providências. Diário Oficial, Brasília, v. 149, n. 76, p. 53, 19 abr. 2012. Seção 1.

EPE - EMPRESA DE PESQUISA ENERGÉTICA. Micro e mini geração distribuída \& baterias - estudos do Plano Decenal de Expansão de Energia 2030. Brasília: EPE, set. 2020. Disponível em: <https://bit.ly/32dyl58> Acesso em: dez. 2020.

\section{BIBLIOGRAFIA COMPLEMENTAR}

BRASIL. Resolução Normativa Aneel no 687, de 24 de novembro de 2015. Altera a Resolução Normativa no 482, de 17 de abril de 2012, e os Módulos 1 e 3 dos Procedimentos de Distribuição - Prodist. Diário Oficial, Brasília, 25 nov. 2015.

. Ministério de Minas e Energia. Boletim mensal de monitoramento do Sistema Elétrico Brasileiro - outubro/2020. Brasília: MME, 2020. Disponível em: <https://bit.ly/2PZchc6>. Acesso em: dez. 2020. 


\section{SITES CONSULTADOS}

- ABEEólica. Disponível em: <http://abeeolica.org.br/>. Acesso em: dez. 2020.

- Absolar. Disponível em: <www.absolar.org.br>. Acesso em: dez. 2020.

- Aldo Solar. Disponível em: <https://www.aldo.com.br/>. Acesso em: dez. 2020.

- Energy Source. Disponível em: <https://energysource.com.br/EnergyS/>. Acesso em: dez. 2020.

- EPE. Disponível em: <www.epe.gov.br>. Acesso em: dez. 2020.

- Solius Solar. Disponível em: <https://solius.com.br/>. Acesso em: dez. 2020.

- Unipower. Disponível em: <https://unipower.com.br/>. Acesso em: dez. 2020. 


\section{O IMPACTO DAS NOVAS TECNOLOGIAS NA DEMANDA DO LÍTIO'}

Eduardo Vale ${ }^{2}$

\section{SINOPSE}

Este texto apresenta uma síntese do estudo sobre o lítio (Li) preparado pelo Ipea no âmbito da cooperação institucional (Termo de Execução Descentralizada - TED) com o Ministério de Minas e Energia (MME). $\mathrm{O}$ artigo oferece um diagnóstico horizontal, embora focado em tópicos selecionados, e uma análise do impacto das novas tecnologias na demanda do lítio. A partir da análise da situação atual, são discutidos cenários prospectivos de modo a referenciar as sugestóes de políticas e açôes setoriais de governo especificamente direcionadas à cadeia industrial do lítio.

Palavras-chave: economia mineral; aquecimento global; lítio; mineração; eletrificação; baterias; energias renováveis.

\section{INTRODUÇÃO}

Em meados dos anos 1990, a massificação no uso de dispositivos eletrônicos portáteis impulsionou a demanda por baterias recarregáveis a base de lítio. A partir de 2008, a importância do metal recebeu impulso com os compromissos internacionais relativos à reduçáo de emissóes de dióxido de carbono para mitigaçáo do aquecimento global. Em diversos países, estão sendo implementadas políticas públicas direcionadas à redução do consumo de combustíveis fósseis, com ênfase no aumento do uso de energias renováveis e no fomento à transição para veículos elétricos.

O relatório Minerals for climate action: the mineral intensity of the clean energy transition, do Banco Mundial, estimou o impacto na demanda de bens minerais selecionados provenientes da expansáo global esperada das energias eólica e solar, assim como a produção de baterias para veículos elétricos ou armazenamento em larga escala até 2050 (Hund et al., 2020). Esses vetores são considerados fundamentais para se alcançar a meta global de reduçáo mínima de $2^{\circ} \mathrm{C}$ no processo de aquecimento. Trata-se de processo intensivo no emprego de bens minerais e cuja intensidade será ampliada. O estudo incluiu o lítio no grupo dos minerais de grande impacto: "bens minerais utilizados por grupo restrito de tecnologias" (Hund et al., 2020, tradução nossa). As estimativas do Banco Mundial apontam para um crescimento de 965\% na demanda de lítio até 2050.

\section{BATERIAS DE ÍON-LÍTIO}

As baterias de íon-lítio são destinadas aos veículos elétricos e ao armazenamento em larga escala da energia gerada pelas fontes renováveis. Registre-se que essas baterias, relativamente às opçóes tecnológicas alternativas, caracterizam-se por oferecer menor peso e maior capacidade de armazenamento por períodos mais longos, além de suportarem alto número de ciclos de carga/descarga. A figura 1 ilustra a importância das baterias de íon-lítio na geração de energia renovável. 
Entre os três principais componentes da bateria de íon-lítio tem-se:

- o anodo, que tem a função de armazenar e liberar os íons de lítio para a corrente elétrica;

- o eletrólito, que encerra os sais de lítio e é o componente principal da bateria, pois possibilita o fluxo de íons entre o anodo e o catodo; e

- o catodo, que desempenha papel fundamental ao possibilitar a geraçáo de corrente elétrica mediante reação química.

Os materiais empregados dependem da tecnologia utilizada nos tipos de baterias:

- lithium cobalt oxide (LCO);

- lithium manganese oxide (LMO);

- lithium iron phosphate (LFP);

- lithium nickel manganese cobalt (NMC); e

- lithium nickel cobalt aluminum oxide (NCA).

\section{FIGURA 1}

Baterias de íon-lítio na geração de energia renovável

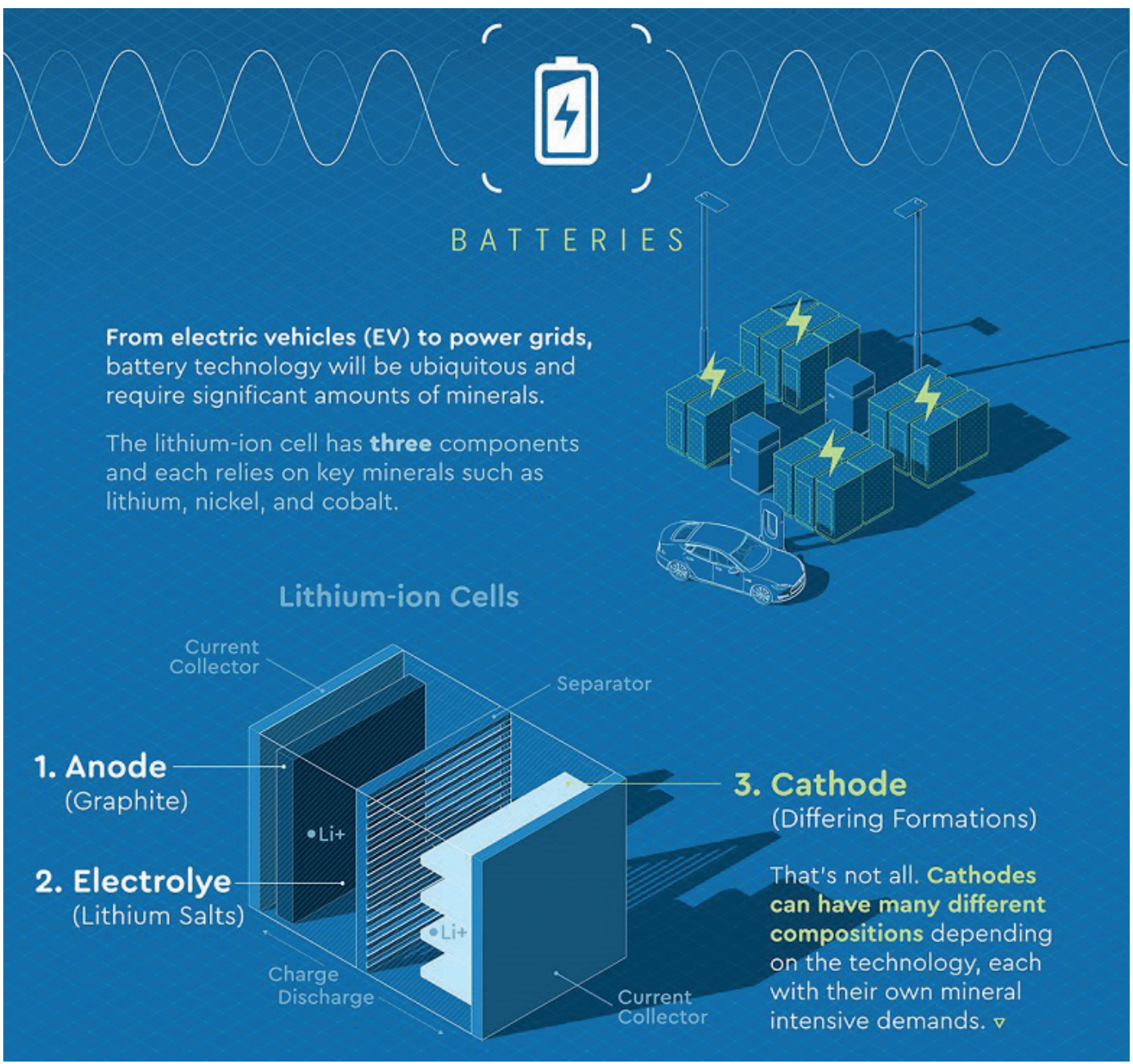

Fonte: Climate-smart mining: minerals for climate action. Disponivel em: <https://bit.ly/3uP1JLh>.

Obs.: Figura cujos leiaute e textos não puderam ser padronizados e revisados em virtude das condições técnicas dos originais (nota do Editorial). 


\section{CONSUMO DE LÍTIO}

O lítio e seus compostos químicos têm uma ampla gama de aplicaçôes na fabricação de baterias (primárias e recarregáveis), em vidro e cerâmica, em graxas lubrificantes, em ligas metálicas, em medicamentos e na indústria nuclear. No perfil setorial agregado do consumo global, tem-se: baterias, 65\%; cerâmica e vidro, 18\%; graxas, 5\%; polímero, 3\%; fundição, 3\%; tratamento do ar, $1 \%$; outros, $5 \%$.

A componente da demanda futura representada pela indústria de baterias é o vetor de maior relevância para o crescimento do consumo de lítio. A título ilustrativo, em 2013, no perfil do consumo mundial, a liderança era do setor de vidro e cerâmica (35\%), seguido por baterias (31\%), graxas lubrificantes (8\%), fundição (6\%); tratamento do ar $(5 \%)$, polímeros (5\%), alumínio (1\%) e outros (9\%). Em apenas seis anos, o segmento de baterias de íon-lítio mais do que dobrou sua participação relativa no consumo de lítio.

\section{DEMANDA DE LÍTIO}

Com o avanço das energias não renováveis e dos veículos elétricos, a trajetória de expansão da demanda estimada por baterias de íon-lítio provocará aumento expressivo na demanda desse mineral. As estimativas da Agência Internacional de Energia (AIE) indicam crescimento acentuado no número de carros elétricos e híbridos, cuja frota deverá evoluir de 7,2 milhóes de veículos elétricos (quatro rodas), em 2019, para cerca de 23 milhôes, em 2030. Nesse contexto, o avanço dos marcos regulatórios e a implementação de estímulos fiscais por países desenvolvidos assumem papel cada vez mais relevante no fomento à aceleração da taxa de penetração de veículos elétricos.

A partir dessas consideraçóes, o vetor de crescimento fundamental da demanda prospectiva de lítio, ao longo da próxima década, é o segmento de baterias do tipo íon-lítio, seja para mobilidade elétrica, seja para o armazenamento de energia em larga escala ou destinado ao segmento de produtos eletrônicos. Em 2030, a participação relativa do segmento de baterias deverá responder por aproximadamente $75 \%$ da demanda do metal. A empresa de consultoria Roskill e a empresa Albermale, maior produtora de lítio do mundo, trabalham com taxas médias de crescimento, para a década de 2020 , ao redor de $20 \%$ ao ano, com expectativa de uma demanda de 1 milhão de toneladas de carbonato de lítio equivalente (LCE) sendo alcançada por volta de 2026/2027 (Heathman, 2020; Albermale, 2020). Essa perspectiva sugere um mercado com pressão sobre os preços e incentivo ao desenvolvimento de novos projetos. No que diz respeito aos demais segmentos consumidores, como vidro, cerâmica, graxas lubrificantes, ligas metálicas, medicamentos e indústria nuclear, as expectativas são de crescimento moderado, ao redor de $5 \%$.

\section{O LÍTIO NO BRASIL}

Ao longo dos últimos dez anos, várias ações de governo foram implementadas para fomentar os minerais considerados estratégicos. Algumas dessas ações estão mencionadas no terceiro artigo desta edição do boletim Radar, referente à grafita. No que concerne especificamente ao lítio, merecem destaque o projeto Avaliação do Potencial do Lítio no Brasil, da Companhia de Pesquisa de Recursos Minerais (CPRM), e o Plano de Ciência, Tecnologia e Inovaçáo para Minerais Estratégicos 2018-2022. Entre as metas e açóes de ciência, tecnologia e inovação (CT\&I) propostas para superar o desafio tecnológico do lítio destaca-se a "Meta 1 - Desenvolver tecnologias e inovaçôes para produção e aplicação de lítio em produtos de alta tecnologia". Para a consecução da meta, são propostas algumas açóes na área de pesquisa, desenvolvimento e inovação (PD\&I). 
A Companhia Brasileira de Lítio (CBL) é a única produtora de lítio no país. Todavia, encontram-se em implantação dois projetos das empresas AMG Mineração e Sigma Mineração. A implantação desses projetos irá alavancar sobremaneira a inserçáo brasileira no mercado internacional. Por sua vez, ao contribuírem para descortinar o potencial mineral do país como produtor de lítio, oferecem lastro inicial para a implantação de uma política setorial direcionada à cadeia industrial do lítio.

Finalmente, a implantação dos primeiros projetos para a produção de baterias no Brasil sinaliza o reconhecimento do grande potencial do mercado interno brasileiro pelo lado da demanda por baterias. Diante dos compromissos internacionais do país, no que concerne à emissão de $\mathrm{CO}_{2}$, merece registro que, em se tratando de veículos elétricos, um dos segmentos que despertam grande interesse inicial é a substituição da grande frota de ônibus urbanos, assim como outras alternativas de mobilidade urbana em consideração, em diversos municípios.

\section{CONCLUSÕES E SUGESTÕES}

Em vários países desenvolvidos, as políticas direcionadas à redução do consumo de combustíveis fósseis e à eletrificaçáo da economia integram o eixo central do processo de retomada do crescimento. Trata-se de processo intensivo no uso de bens minerais.

O lítio não é considerado um metal raro. Não obstante, o predomínio do lítio como mineral crucial permeando a maioria das rotas tecnológicas alternativas para produção de baterias associado ao suprimento fortemente concentrado em termos de países e de empresas alçaram o metal, sob as óticas da segurança nacional e da garantia de suprimento, à categoria de mineral crítico. No plano nacional, a magnitude dos recursos e das reservas de lítio do país, assim como a dimensão do seu mercado doméstico potencial para baterias de íon-lítio, tanto para armazenamento quanto para veículos elétricos, o posiciona entre os minerais prioritários no que diz respeito à definição de uma política mineral específica.

Os fundamentos da demanda no longo prazo parecem sólidos e bem-colocados. Ao longo da década, as perspectivas para a demanda de lítio são excelentes. A despeito das condiçóes adversas de mercado após o impacto da Covid-19, que deverão perdurar até o final de 2021, existe um consenso quanto à robustez da demanda do lítio ao longo da década. O impacto nas decisóes de investimentos e a relativa intensidade do processo atual de ajustamento da oferta, especialmente no que concerne às suspensôes e às postergaçóes de projetos de expansão e de implantação, sugerem a possibilidade de que, a partir de 2022/2023, tenha início uma trajetória de elevação persistente do preço. Níveis de produção significativamente abaixo da demanda a partir de 2023 são prováveis. Este desequilíbrio potencial seria fruto da discrepância entre a alta elasticidade da demanda por baterias, em resposta à aceleração na demanda por veículos elétricos e por armazenamento de energia, diante da relativa inelasticidade do suprimento de concentrado de lítio no médio prazo, especialmente após a pandemia.

Em nível de sugestôes, são focalizadas três dimensões da economia do lítio: suprimento (exploração e produção mineral), tecnologia e demanda. Pelo lado da exploração mineral, visando acelerar o conhecimento dos recursos minerais, sugere-se a reavaliação dos resultados alcançados no projeto Avaliação do Potencial do Lítio no Brasil, da CPRM (Paes, 2018). O objetivo é selecionar subáreas específicas de alta prioridade, que justifiquem serem revisitadas para maior detalhamento e adensamento de informaçóes de geologia econômica (escala, amostragem, abertura de trincheiras etc.) em configuração e formato conceitual o mais próximo possível das necessidades do processo decisório do setor privado. Nesse contexto, inserem-se as questôes relativas ao aperfeiçoamento do modelo geológico dos depósitos de lítio, à identificação de novas áreas potenciais e à proposição de um modelo exploratório para os pegmatitos do tipo lítio-césio-tântalo (LCT). Pelo lado da produção, sugere-se atribuir prioridade e dinamizar a liberação dos processos de direitos minerários para lítio. 
Sob a ótica da tecnologia, sugere-se a realização de um inventário dos projetos de pesquisa tecnológica para o lítio: já executados, em execução ou previstos. Esse levantamento poderia ser realizado pelo Centro de Tecnologia Mineral (Cetem). Um dos gargalos fundamentais é a conversão química para a produção de hidróxido de lítio grau bateria. Um projeto em escala piloto seria um bom começo. Entre as opçóes, o estabelecimento de parcerias para cooperação internacional é uma alternativa que merece ser avaliada. Nesse caso, acredita-se que a Índia reúna características ideais que a credenciam como potencial parceiro a ser considerado. Finalmente, sob a ótica da demanda, tendo em vista a expansão acelerada das energias eólica e solar no país e o grande mercado potencial para veículos elétricos, sugere-se a realização de estudo prospectivo sobre a demanda de baterias.

\section{REFERÊNCIAS}

ALBERMALE. Investor presentation. In: JP MORGAN INDUSTRIALS CONFERENCE, 2020. Anais... Albermale, 2020. Disponível em: <https://bit.ly/3uP5hgz>. Acesso em: 25 jun. 2020.

HEATHMAN, O. Lithium: over 50\% of spodumene supply marginal in Q2 2020. Roskill, 27 Aug. 2020. Disponível em: <https://bit.ly/3dV14kA>. Acesso em: 25 jun. 2020.

HUND, K. et al. Minerals for climate action: the mineral intensity of the clean energy transition. Washington: World Bank, 2020. Disponível em: <https://bit.ly/3dhUuG3>.

PAES, V. J. de C. Avaliação do potencial do lítio no Brasil: ações, principais resultados, perspectivas atuais e futuras. Brasília: CPRM, 2018.

\section{BIBLIOGRAFIA COMPLEMENTAR}

ARROBAS, D. P. et al. The growing role of minerals and metals for a low carbon future. Washington: World Bank; EGPS, June 2017. (Working Paper, n. 117581). Disponível em: <https://bit.ly/2Q44TvV>.

VALE, E. Impacto das novas tecnologias na demanda mineral: o caso do lítio. Brasília: Ipea, ago. 2020. 86 p. 



\section{O IMPACTO DAS NOVAS TECNOLOGIAS NA DEMANDA DA GRAFITA ${ }^{1}$}

Eduardo Vale ${ }^{2}$

\section{SINOPSE}

O texto apresenta uma síntese do estudo sobre a grafita $(\mathrm{C})$ preparado pelo Ipea no âmbito da cooperação institucional (TED) com o MME. O relatório de pesquisa oferece um diagnóstico horizontal, embora focado em tópicos selecionados, e uma análise do impacto das novas tecnologias na demanda da grafita. A partir da análise da situação atual, são discutidos cenários prospectivos, de modo a referenciar as sugestôes de políticas e açôes setoriais de governo especificamente direcionadas à cadeia industrial da grafita.

Palavras-chave: economia mineral; aquecimento global; grafita; mineração; eletrificação; baterias; energias renováveis.

\section{AQUECIMENTO GLOBAL}

Os esforços internacionais direcionados à redução do aquecimento global configuram processo em curso acelerado e irreversível. Em diversos países, estão sendo implementadas políticas públicas direcionadas à redução do consumo de combustíveis fósseis, ao aumento do uso de energias renováveis e à substituição de veículos movidos à combustão para veículos elétricos. Essas políticas, diga-se de passagem, estão no centro da agenda de política econômica pós-Covid-19 de vários países desenvolvidos como eixo central do processo de retomada do crescimento.

As açôes planejadas enfatizam o aumento no uso das energias solar e eólica e o fomento à transição para veículos elétricos e híbridos. A gravidade da ameaça representada pelo aquecimento global aumentou a urgência do emprego de fontes renováveis que ajudem a descarbonizar a matriz energética. Em paralelo, avança de forma célere a demanda por veículos elétricos e híbridos - de passageiros e também de carga -, estimulando o processo conhecido como eletrificação da economia.

\section{INICIATIVAS INSTITUCIONAIS}

O relatório Minerals for Climate Action: the mineral intensity of the clean energy transition, publicado pelo Banco Mundial, estimou o impacto na demanda de bens minerais selecionados provenientes da expansão global esperada das energias eólica e solar, assim como da demanda por baterias até 2050 (Hund et al., 2020). Esses vetores são considerados fundamentais para alcançar a meta global de redução mínima de $2{ }^{\circ} \mathrm{C}$ no processo de aquecimento. O estudo incluiu a grafita no grupo dos minerais de grande impacto: "bens minerais utilizados por grupo restrito de tecnologias".

A grafita é destacada pelo uso fundamental na produção do anodo utilizado nas baterias de íon-lítio destinadas aos veículos elétricos e ao armazenamento em larga escala da energia gerada pelas fontes renováveis. As estimativas do Banco Mundial apontam para um crescimento de 383\% na demanda de grafita até 2050.

1. DOI: http://dx.doi.org/10.38116/radar65art3

2. Pesquisador do Subprograma de Pesquisa para o Desenvolvimento Nacional (PNPD) na Diretoria de Estudos e Políticas Setoriais de Inovação e Infraestrutura (Diset) do Ipea. E-mail: <edu.bamburra@gmail.com>. 
A figura 1 apresenta os impactos estimados pelo Banco Mundial na demanda de vários bens minerais para o período que vai de 2017 a 2050.

Nos exercícios prospectivos do Banco Mundial, fica evidenciada a interdependência entre a expansão dos sistemas econômicos baseados na adoção das novas tecnologias e o aumento expressivo na produção mineral global que será requerido. Trata-se de processo intensivo no emprego de bens minerais e cuja intensidade será ampliada. Por outro lado, a expansão da mineração global, em resposta ao impacto da demanda derivada da adoção e disseminação das novas tecnologias, deverá ocorrer, concomitantemente, sob os paradigmas da sustentabilidade e da transição operacional comprometida com a minimização da emissão de carbono.

De acordo com a Agência Internacional de Energia (AIE), a implementação de marcos regulatórios e de medidas fiscais por países desenvolvidos assume papel cada vez mais relevante, tanto no fomento à aceleração das taxas de penetração das energias renováveis na matriz energética global quanto no aumento da frota de veículos elétricos. No âmbito da União Europeia (UE), o lançamento do plano de recuperação econômica European Green Deal contempla investimentos de aproximadamente US\$ 826 bilhóes. O foco é a redução da emissão de $\mathrm{CO}_{2}$, de modo a tornar a UE neutra, do ponto de vista climático, em 2050.

\section{FIGURA 1}

Demanda de bens minerais

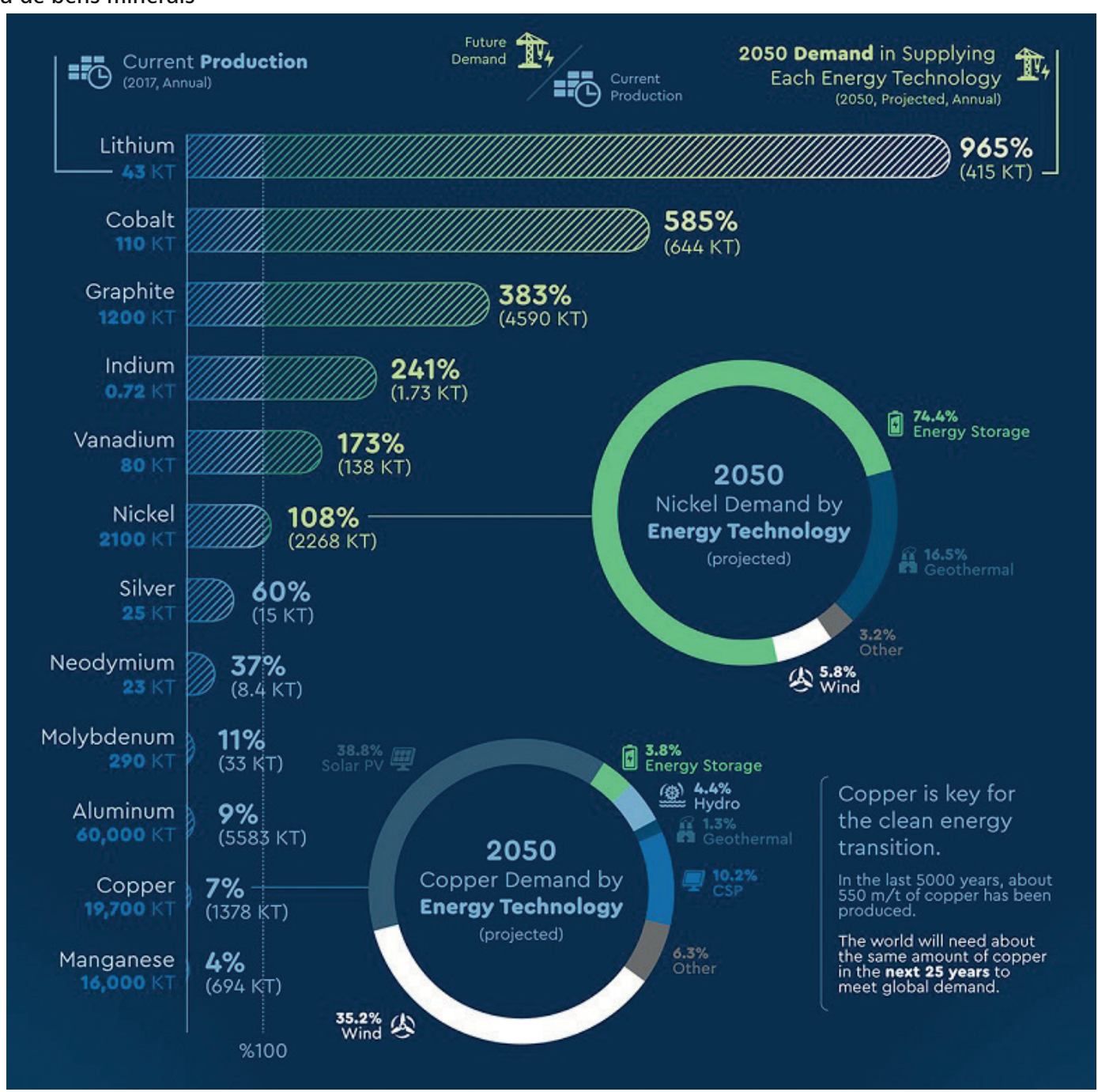

Fonte: Climate-smart mining: minerals for climate action. Disponível em: <https://bit.ly/3uP1JLh>.

Obs.: Figura cujos leiaute e textos não puderam ser padronizados e revisados em virtude das condições técnicas dos originais (nota do Editorial). 
Por sua vez, a Comissão Europeia lançou o documento Resiliência em Matérias-Primas Essenciais (2020), com os seguintes objetivos: i) identificar desafios atuais e futuros para a redução da dependência externa da Europa em materiais críticos; ii) diversificar fontes de suprimento; iii) assegurar o uso eficiente dos recursos; e iv) adotar fundamentos de economia circular em condiçôes de sustentabilidade. Nesse contexto, cabe ainda mencionar a criação das seguintes entidades: Global Battery Alliance (GBA), European Battery Alliance (EBA) e European Raw Materials Alliance (ERMA).

\section{CONSUMO DE GRAFITA}

Muito embora a grafita $(\mathrm{C})$ seja um mineral não metálico, ela apresenta várias propriedades dos minerais metálicos. Seu amplo espectro de características proporciona uma gama diversificada de aplicaçóes industriais e tecnológicas, tais como:

- refratários para a fundição contínua, eletrodos, produção de extrudados, pós-metálicos e elevação do teor de carbono;

- aplicaçóes em reatores nucleares e compósitos de alta resistência para energia eólica;

- indústria aeroespacial;

- anodo para baterias (o anodo tem a função de armazenar e liberar os íons de lítio para a corrente elétrica); e

- lápis, lubrificantes, retardantes de fogo e materiais de fricção, escovas de motores elétricos.

Na sequência, tem-se o perfil setorial agregado do consumo global: refratários (35\%); baterias (25\%); lubrificantes e fundição (10\%); siderurgia (7\%); lápis (4\%); outros (19\%).

Atualmente, cerca de dois terços da demanda por concentrado de grafita é derivada do setor industrial, e um terço do segmento de baterias. No período que vai de 2012 a 2019, a participação relativa das baterias no consumo de grafita aumentou cerca de $150 \%$. Para os próximos dez anos, pelo menos, as perspectivas para a demanda de grafita são excelentes. Segundo a empresa Benchmark Mineral Intelligence (2020), o segmento de baterias deverá responder por cerca de $50 \%$ da demanda por volta de 2025 , alcançando $75 \%$ ao final da década.

No que diz respeito aos demais segmentos consumidores, tais como refratários, lubrificantes, fundição e pósmetálicos, entre outros, as expectativas são de crescimento moderado na faixa de 5\% a 7\% ao ano. Destaque-se que a demanda de grafita como insumo para retardante de fogo deverá apresentar crescimento acima da média dos demais segmentos consumidores por conta do avanço no arcabouço legal específico.

A partir dessas consideraçóes, o vetor de crescimento fundamental da demanda de grafita, ao longo dessa década, é o segmento de baterias do tipo íon-lítio para veículos elétricos e híbridos (de duas, três ou quatro rodas), para armazenamento de energia em larga escala e para o segmento de produtos eletrônicos em geral.

\section{SITUAÇÃO DA GRAFITA NO BRASIL}

No Brasil, a grafita está inserida no grupo de minerais estratégicos por suas aplicaçóes em produtos e processos de alta tecnologia. Segundo o United States Geological Survey (USGS), as reservas brasileiras estão estimadas em 72 milhóes de toneladas. As reservas de grafita do país representam $24 \%$ das reservas mundiais. No que diz respeito à produção, a estimativa do USGS é de 96 mil toneladas de carbono grafítico $(\mathrm{Cg})$. 
Por outro lado, a dimensão do mercado interno potencial para baterias de íon-lítio, a magnitude e a diversificação do setor industrial e os avanços tecnológicos em curso posicionam a grafita entre os minerais prioritários para a política mineral. Tanto o setor público quanto o privado possuem diversas açóes voltadas para o mineral, com destaque para as seguintes:

- projeto Avaliação do Potencial da Grafita no Brasil, fase 1 - PAPGB (Sousa e Matos, 2020);

- Inova Mineral - plano de desenvolvimento, sustentabilidade e inovação do setor de mineração e transformação mineral (MME, ABDI, MCTI, CETEM, MDIC, empresas e ICTs);

- Política de Apoio ao Licenciamento Ambiental de Projetos de Investimentos para a Produção de Minerais Estratégicos;

- Grupo de Trabalho Brasil-Estados Unidos "para avançar a cooperação bilateral em minerais essenciais para a segurança, a prosperidade e o desenvolvimento sustentável de ambos os países”; ${ }^{3}$

- início da produção de baterias do tipo fosfato-lítio-ferro (LFP) no Polo Industrial de Manaus pela empresa chinesa BYD;

- instalação de fábrica para produção de células de baterias de lítio-enxofre na cidade de Juiz de Fora (MG) pela empresa britânica Oxis Energy;

- criação do MackGraphe - centro de pesquisas avançadas em grafeno, nanomateriais e nanotecnologias; ${ }^{4} \mathrm{e}$

- projeto MGgrafeno - implementaçáo da primeira planta-piloto de grafeno do Brasil pela Companhia de Desenvolvimento do Estado de Minas Gerais, em parceria com o Centro de Desenvolvimento da Tecnologia Nuclear/Comissão Nacional de Energia Nuclear e com a Universidade Federal de Minas Gerais. ${ }^{5}$

\section{COMENTÁRIOS FINAIS}

Em vários países desenvolvidos, as políticas direcionadas à redução do consumo de combustíveis fósseis e à eletrificação da economia integram o eixo central do processo de retomada do crescimento. Trata-se de processo intensivo no uso de bens minerais. Para os governos desses países, sob as óticas da segurança nacional e da garantia de suprimento, a dinâmica, as sinergias e a transcendência global da agenda sobre o clima alçaram a grafita à categoria de mineral crítico. Nesse contexto, ressalta-se a concentração geográfica em termos de origem e destinação desse mineral, especialmente no que concerne ao processamento químico-industrial situado na Ásia.

A magnitude das reservas de grafita do Brasil, as inúmeras aplicaçôes industriais, a dimensão do mercado interno potencial para baterias de íon-lítio e a produção de materiais e produtos avançados, como os derivados do grafeno, apontam para a oportunidade de agregação de valor na cadeia industrial do país.

Os fundamentos da demanda no longo prazo parecem sólidos e bem colocados. Ao longo da década, as perspectivas para a demanda de grafita são excelentes. O segmento de baterias deverá responder por cerca de $50 \%$ da demanda por volta de 2025, alcançando $75 \%$ em 2030. A empresa de consultoria Benchmark Mineral Intelligence estima uma demanda de anodo ao redor de 2,2 milhóes de toneladas, em 2024, ultrapassando 3,5 milhôes de toneladas ao final da década. O aumento da participação da grafita natural parece inevitável, tendo em vista o seu custo de produção mais baixo (custo de energia) e sua estrutura de produção mais sustentável, em comparação à grafita sintética.

3. Disponível em: <https://bit.ly/3v5dflv>.

4. Disponível em: <https://www.mackenzie.br/en/mackgraphe/>.

5. Disponível em: <https://www.mggrafeno.com.br/>. 
Ao longo dos últimos dez anos, em que pese a entrada de outros produtores, a produção de grafita natural manteve-se relativamente estável. Contudo, é inegável que, a despeito das altas taxas de crescimento da demanda pelo setor de baterias, os níveis de preços da grafita não sinalizam, até o presente, o impacto dessa demanda adicional. As principais consultorias especializadas não vislumbram aumentos de preços até que a demanda alcance patamares capazes de pressionar a capacidade instalada prevista.

É oportuno registrar que essas estimativas antecederam o resultado das eleiçóes americanas. Conforme anunciado pelo governo eleito, haverá uma ênfase no aprofundamento do processo de eletrificação e do desenvolvimento de energias renováveis. $\mathrm{Na}$ ausência de aumentos substanciais da produção mundial de grafita, considerando as elevadas taxas de crescimento esperadas para a demanda de grafita, esperam-se um mercado deficitário, já a partir de 2024, e uma trajetória de crescimento acelerada.

Em nível de sugestóes, pelo lado do suprimento, cabe acelerar o conhecimento do potencial de grafita do país em escala e formatação compatíveis com as necessidades dos projetos de exploraçáo mineral do setor privado. Pelo lado da produção mineral, dinamizar a liberação de direitos minerários referentes à grafita.

Sob a ótica da tecnologia, é fundamental dispor de uma visão agregada da carteira de projetos de pesquisa relacionados à grafita. A realização de inventário dos projetos já executados, em execução ou previstos pode ser muito útil. O objetivo é posicionar o governo acerca da situação atual e oferecer maior lucidez sobre a eficácia e a aderência da alocaçáo dos recursos às prioridades do país. Nesse contexto, a análise das oportunidades e dos obstáculos e o desenvolvimento de estratégia voltada para aumento da agregação de valor ao longo da cadeia industrial da grafita sugerem as etapas de micronização e de produção da grafita esférica purificada como objetivos a serem perseguidos.

Considerando a expansão acelerada das energias eólica e solar, a demanda por baterias para armazenamento já está colocada. Falta aprofundar o conhecimento sobre esse vetor, sua dinâmica e suas implicaçóes. Assim sendo, sugere-se a realização de estudo prospectivo sobre a demanda potencial de grafita para o segmento de baterias. Não obstante, tendo em vista as inúmeras aplicaçóes industriais, o escopo do estudo deve ser mais amplo e oferecer suporte à definição de uma política mineral específica para a cadeia industrial de valor da grafita.

\section{REFERÊNCIAS}

BENCHMARK MINERAL INTELLIGENCE. Lithium ion battery megafactories assessment. London: Benchmark, Nov. 2020.

COMISSÃO EUROPEIA. Resiliência em matérias-primas essenciais: o caminho a seguir para mais segurança e sustentabilidade. Bruxelas: Comissão Europeia, 3 set. 2020. (Comunicado, n. 474). Disponível em: <https://bit.ly/2P6MUVp>. HUND, K. et al. Minerals for climate action: the mineral intensity of the clean energy transition. Washington: World Bank, 2020. Disponível em: <https://bit.ly/3dhUuG3>.

SOUSA, M. J.; MATOS, D. R. (Org.). Projeto Avaliaçáo do Potencial da Grafita no Brasil: fase 1. São Paulo: CPRM, 2020. (Série Minerais Estratégicos, n. 5). Disponível em: <http://rigeo.cprm.gov.br/jspui/handle/doc/21910>.

VALE, E. Impacto das novas tecnologias na demanda mineral: o caso da grafita. Brasília: Ipea, dez. 2020. 86 p. 



\section{EVOLUÇÃO RECENTE DO MARKET SHARE DAS EXPORTAÇÕES MINERAIS BRASILEIRAS'}

Daniel Monte Cardoso²

\section{SINOPSE}

O Brasil é um dos principais exportadores de commodities agrícolas e mundiais e atualmente detém uma posição bastante importante no que se refere ao mercado internacional de bens minerais. Após o boom de commodities minerais (entre 2003 e 2013), o país ampliou sua produção em alguns segmentos (cobre, ouro, níquel, entre outros) e consolidou-se em segmentos mais tradicionais (minério de ferro). $\mathrm{O}$ artigo se propóe a analisar a evolução do market share e o do Índice de Vantagem Comparativa Revelada (IVCR) dos principais produtos de exportação mineral brasileiros entre 2015 e 2019, enfatizando a organização geográfica dos principais centros produtores.

Palavras-chave: mineração; exportaçôes; vantagens comparativas; organização espacial.

\section{INTRODUÇÃO}

O Brasil é um dos maiores produtores do mercado mundial de commodities minerais, detendo grandes parcelas do mercado de insumos metalúrgicos e produtos de metal de base. Conforme apresentado pelo documento Informe mineral - $2^{\circ}$ semestre de 2019, quatro substâncias minerais apresentaram valor exportado acima de US\$ 1 bilhão no segundo semestre de 2019 (ANM, 2020), contemplando, em ordem de valor exportado: o minério de ferro (finos e pelotas); o ouro; o minério de cobre; e o ferronióbio (produto resultado do processamento do mineral pirocloro).

O principal objetivo deste artigo é apresentar a evolução da participação de determinados segmentos da mineração brasileira (minério de ferro, ouro, minério de cobre e ferronióbio) no mercado mundial de commodities minerais por meio do cálculo do market share e do Índice de Vantagem Comparativa Revelada (IVCR), ${ }^{3}$ discorrendo sobre a organizaçáo geográfica dos centros produtores.

No caso do IVCR, valores acima da unidade $(1,0)$ apontam que o país apresenta vantagens comparativas no segmento analisado, e valores abaixo da unidade significam o contrário. Os dados utilizados estão disponíveis na plataforma Trademap (ITC). ${ }^{4}$ Os resultados estão todos dispostos na tabela 1 .

1. DOI: http://dx.doi.org/10.38116/radar65art4

2. Pesquisador do Subprograma de Pesquisa para o Desenvolvimento Nacional (PNPD) na Diretoria de Estudos e Políticas Setoriais de Inovação e Infraestrutura (Diset) do Ipea.E-mail: <daniel.cardoso@ipea.gov.br>.

3. O IVCR é um indicador de vantagem comparativa e foi desenvolvido por Balassa (1965), sendo obtido por meio de: IVCR $R_{i j}=\left(X_{i j} / X_{i}\right) /\left(X_{z j} / X_{z}\right)$, em que: $j=$ produto analisado; $i=$ país em questão; $z=$ mundo.

4. Ver: <https://www.trademap.org/>. 


\section{RESULTADOS}

O minério de ferro é um dos principais produtos da pauta de exportaçáo brasileira e o principal produto da pauta de exportaçáo mineral do país. De acordo com o ANM (2020), o Brasil exporta fundamentalmente minério de ferro (granulado, sinter feed e pellet feed) e pelotas de minério de ferro.

Sob a ótica da oferta global, Brasil e Austrália detêm a maior parte das exportaçóes mundiais (aproximadamente $85 \%)$. O maior comprador mundial de minério de ferro é a China (cerca de $70 \%$ das importaçóes totais), cujo uso se dá quase que exclusivamente nos altos fornos siderúrgicos para a produção de aço (Carvalho et al., 2014).

No Brasil, o grupo Vale concentra a produção de minério de ferro (cerca de $70 \%$ do valor comercializado) em Minas Gerais (Sistema Sudeste) - localizado no quadrilátero ferrífero, abrangendo as minas de Itabira, Minas Centrais e Mariana -, e no Pará (Sistema Norte) - localizado na regiáo de Carajás, abrangendo as minas de Parauapebas e Canaã dos Carajás (Vale, 2020). Além desses dois polos, destaca-se a produção do Sistema Sul Vargem Grande e Paraopeba -, também situado no quadrilátero ferrífero (Vale, 2020). Há também a produção da Anglo American Brasil, ${ }^{5}$ cujas minas e usinas de processamento estấo instaladas nos municípios de Conceição do Mato Dentro e Alvorada de Minas, ambos no estado de Minas Gerais.

Nos últimos anos, o Brasil apresentou um desempenho relativamente estável no que concerne à participação no comércio mundial de minério de ferro (em torno de $20 \%$ ) e na evoluçáo do IVCR (em torno de 16). Nesse sentido, o país detém uma posição bastante competitiva no mercado, visto que sedia uma das maiores empresas produtoras (Vale) e possui grandes reservas de alto teor de pureza (região de Carajás).

$\mathrm{O}$ mercado de pelotas de minério de ferro, diferentemente do mercado de minério de ferro, é mais pulverizado. Atualmente, o Brasil é o segundo maior exportador, à frente da Suécia e atrás da África do Sul. Nos últimos anos, apresentou uma forte perda em termos de market share (27,8\% para 13\%) e declínio do IVCR $(23,8$ para 13,8).

O ouro é o segundo maior em valor das exportações minerais brasileiras (aproximadamente US\$ 3,5 bilhōes, em 2019). Apesar do pequeno volume de produção e comercialização, o grama do ouro é bastante valioso, em virtude de sua utilizaçáo no mercado de joias e de sua importância como reserva de valor, sobretudo em situaçóes de instabilidade nos mercados financeiros globais, como a atual, em que vários países têm intensificado sua corrida para ampliar o estoque de ouro metálico. O Brasil exporta cerca de $60 \%$ de sua produção em forma de ouro em barra, fios e perfis de seção maciça (uso monetário) e aproximadamente $40 \%$ do total em forma de bulhão dourado, de uso náo monetário.

A maior parte do ouro brasileiro é escoado por vias áreas (Aeroportos de Guarulhos, Brasília e Manaus), em função de seu baixo volume. Em sua maioria, é produzido pelas empresas Kinross (Paracatu-MG), Anglogold Ashanti (Nova Lima-MG e Crixás-GO), Mineração Pedra Branca do Amapari (Pedra Branca do Amapari-AP) e Mineraçáo Jacobina (Jacobina-BA). Atualmente, o Brasil detém uma parcela pequena das exportaçóes mundiais (cerca de $1 \%)$ e, apesar de ter melhorado sua posição internacional $(0,6$ para 1,0$)$, não se pode dizer que o país apresente vantagem comparativa no segmento. 
TABELA 1

Exportações minerais e IVCR (2015-2019)

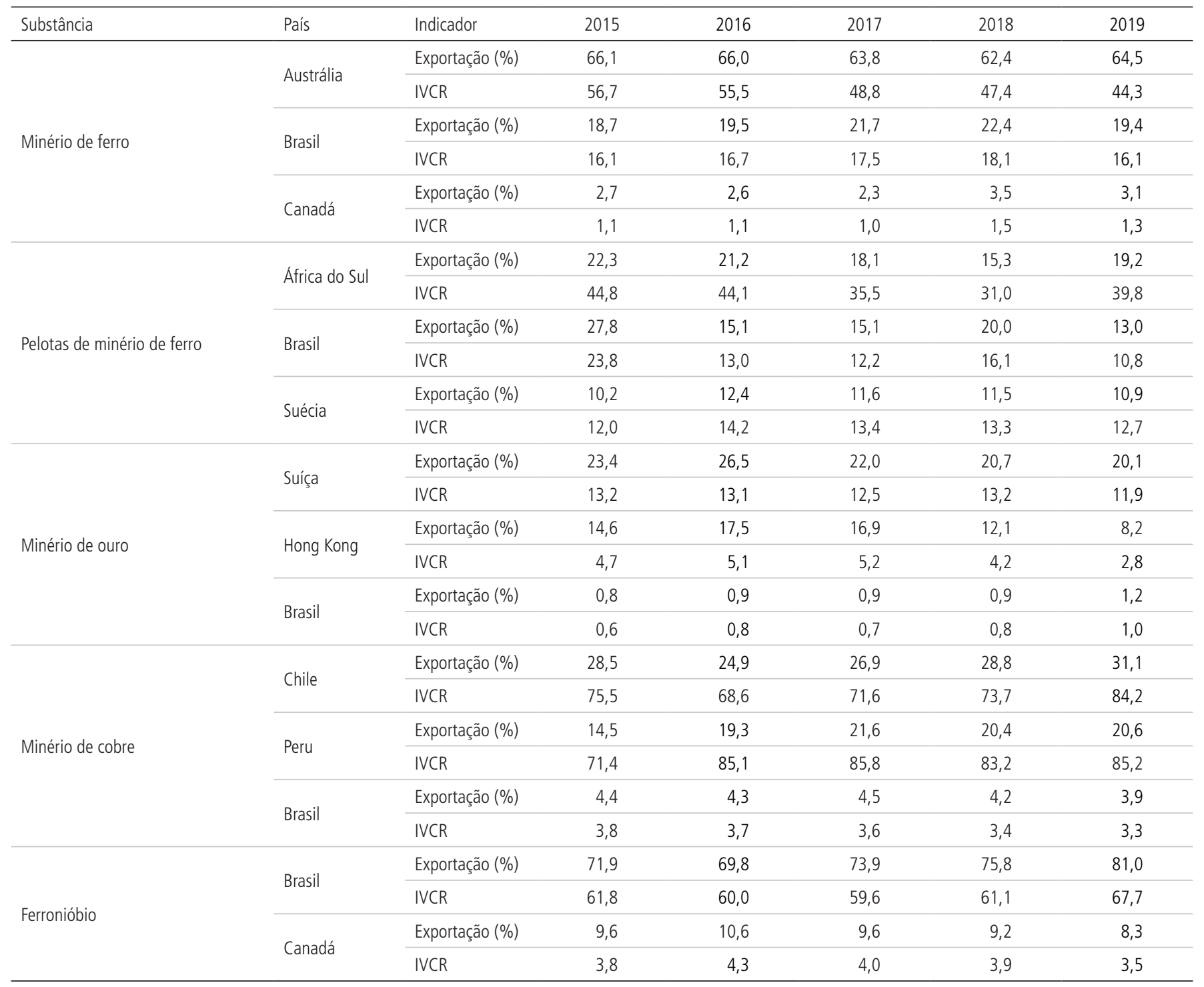

Fonte: Trademap/ITC.

O cobre é um dos principais insumos da produção metalúrgica no mundo e, nos últimos anos, passou a figurar entre os principais produtos minerais exportados pelo Brasil. A maior parte do cobre exportado é comercializado na forma de concentrado de cobre (cerca de $80 \%$ do total), enquanto o restante é vendido na forma de sulfetos de cobre.

O Brasil concentra sua produção nos estados do Pará, Goiás e Bahia. No Pará, há dois complexos de exploração do minério de cobre: as minas de Sossego e Sequeirinho, no município de Canaã dos Carajás, e a mina de Salobo, situada no município de Marabá e administrada pela subsidiária da Vale, Salobo S.A. (Vale, 2020). A parte da produção escoada pelo porto de Vitória (cerca de $20 \%$ do total) refere-se à produção da mina de Chapada (Alto Horizonte, Goiás), explorada pela empresa sueco-canadense Lundin Mining. ${ }^{6}$ Outra parte importante das exportaçóes de minério de cobre é escoada pelo porto de Aracaju, correspondendo ao produto do beneficiamento do minério de cobre efetuado pela empresa Mineração Caraíba, cujas minas estão situadas em Jaguarari (Bahia). 
Apesar do incremento das exportaçóes brasileiras de cobre, o mercado mundial ainda é bastante concentrado, sendo praticamente dominado por Chile e Peru, que concentram não somente a produçáo como a maior parte das reservas minerais (Rocio et al., 2012). Nos últimos anos, a participação brasileira no total das exportações de cobre girou em torno de 4\%, enquanto os maiores exportadores (Chile e Peru) detinham cerca de $50 \%$ do total das exportaçóes mundiais. Em termos de IVCR, o Brasil apresentou um ligeiro declínio nos últimos anos (de 3,8 para 3,3).

No caso do nióbio, o Brasil está bem-posicionado no mercado mundial. O nióbio é hoje um dos principais minerais estratégicos, ${ }^{7}$ e o Brasil possui uma das maiores reservas do mundo. $\mathrm{Na}$ atividade de extração, obtém-se o mineral pirocloro, que é processado na forma de ferronióbio, óxidos especiais, ligas especiais e nióbio metálico. ${ }^{8}$ A maior parte da produção brasileira advém das plantas da Companhia Brasileira de Mineração e Metalurgia (CBMM), em Araxá (Minas Gerais). O restante é oriundo das plantas de Ouvidor, no estado de Goiás, operadas pela Niobras, empresa subsidiária da chinesa China Molybdenum (CMOC).

O Brasil detém, ao lado do Canadá, praticamente todo o mercado de ferronióbio no mundo (quase $90 \%$ do total exportado, sendo $81 \%$ do Brasil e $8,3 \%$ do Canadá) e vem apresentando crescentes vantagens comparativas na exportação desse mineral nos últimos anos (o IVCR saiu de 61,8 para 67,7).

Apesar de as ligas de ferronióbio serem muito utilizadas em novas aplicações e materiais industriais, o nióbio pode ser facilmente substituído por vanádio e titânio (Seer e Moraes, 2018) e, em alguns casos, por tungstênio, tântalo ou molibdênio. Assim, a existência de vastas reservas desse mineral no subsolo brasileiro não é garantia de um bom posicionamento no mercado mundial, e a extração de valor econômico do nióbio depende de outros fatores, como acordos comerciais com países e/ou empresas para garantir sua preferência como insumo industrial.

\section{CONSIDERAÇÕES FINAIS}

O último ciclo de commodities minerais, que terminou em 2013, favoreceu a inserção brasileira no mercado mundial de bens minerais, propiciando a abertura de novas frentes de expansão mineral. Nesse sentido, o Brasil consolidou sua posição global de exportador de minério de ferro e ferronióbio e favoreceu a expansão da produção de minério de cobre e o aumento do valor exportado do minério de ouro, particularmente influenciado pela elevação de seu preço no mercado internacional.

Em que pese esses avanços, o Brasil ainda pode expandir seu market share na mineração mundial. O minério de ouro, por exemplo, pode ganhar uma importância maior no futuro, em virtude da contínua valorização e das possibilidades de extração e processamento. Além dos minerais em posição relevante, há ainda: novos minerais a serem explorados com aplicaçôes em novas ligas metálicas; materiais como o lítio, largamente empregado em baterias de veículos automotores elétricos; e minerais terras raras (TRs), cuja utilização é feita em vários segmentos industriais de ponta. ${ }^{9}$

7. 0 nióbio é um dos principais minerais estratégicos, em virtude de sua utilização em materiais e tecnologias de ponta. De acordo com Bruziquesi et al. (2019): "0 nióbio, nos últimos anos, vem despertando interesse por parte de pesquisadores e do governo em virtude das propriedades interessantes, quando usado em ligas metálicas, como elevada resistência mecânica e maleabilidade. 0 nióbio também é utilizado na fabricação de vidros especiais, tais como lentes, películas de revestimento e capacitores cerâmicos. Quando usados como materiais anódicos em baterias de íons-lítio, esse metal (na forma de óxidos) proporciona alta capacidade volumétrica além de ser aplicado como supercapacitores híbridos. Na aplicação em catálise, área importante para a indústria química e petrolífera nacional, catalisadores a base de nióbio geralmente apresentam boa estabilidade química, acidez e versatilidade, ocupando um importante papel em reações catalíticas oxidativa".

8. Ver em: <https://cbmm.com/pt/our-company/operations>; <https://cmocbrasil.com/br/negocios/niobio>.

9. "Os usos e aplicações dos 17 elementos constituintes do grupo das TRs concentram-se em áreas de alta tecnologia e não são conhecidos até o momento substitutos que proporcionem o mesmo desempenho. Nas tecnologias relacionadas a energias limpas e controle de emissões atmosféricas, por exemplo, as cadeias produtivas são fortemente dependentes de TRs, essenciais na fabricação de ímãs permanentes, usados em turbinas eólicas e veículos elétricos; baterias avançadas, utilizadas em veículos elétricos; semicondutores filmes-finos, usados em sistemas de energia fotovoltaica; e fósforos, utilizados em sistemas de iluminação mais eficientes" (CGEE, 2013). 
Assim, é sabida a existência de várias reservas minerais de segmentos de maior competitividade recente e de segmentos minerais de importância estratégica futura. Maiores investimentos em pesquisa e prospecçáo de reservas estratégicas poderão posicionar o Brasil de forma mais competitiva no mercado mundial, indo para além dos mercados cativos que o país já possui.

\section{REFERÊNCIAS}

ANM - AGÊNCIA NACIONAL DE MINERAÇÃO. Informe mineral: julho-dezembro de 2019. Brasília: ANM, jul. 2020. BALASSA, B. Trade liberalization and "revealed" comparative advantage. The Manchester School of Economic and Social Studies, Oxford, v. 33, n. 2, p. 99-123, 1965.

BRUZIQUESI, C. G. O. et al. Nióbio: um elemento químico estratégico para o Brasil. Química Nova, São Paulo, v. 42, n. 10 , out. 2019.

CARVALHO, P. S. L. et al. (2014). Minério de ferro. BNDES Setorial, Rio de Janeiro, n. 39, p. 197-234, mar. 2014.

CGEE - CENTRO DE GESTÃO E ESTUDOS ESTRATÉGICOS. Uso e aplicaçóes de terras raras no Brasil: $2012-$ 2030. Brasília: Centro de Gestão e Estudos Estratégicos, 2013.

ROCIO, M. A. R. et al. Perspectivas atuais da indústria de cobre no Brasil. BNDES Setorial, Rio de Janeiro, n. 36, p. 397-428, set. 2012.

SEER, N. J.; MORAES, L. C. Nióbio. In: PEDROSA-SOARES, A. C.; VOLL, E.; CUNHA, E. C. (Coord.). Recursos minerais de Minas Gerais on line: síntese do conhecimento sobre as riquezas minerais, história geológica, e meio ambiente e mineração de Minas Gerais. Belo Horizonte: Codemge, 2018.

VALE. Relatório anual 20-F. Rio de Janeiro: Vale, 2020. 



\section{IMPACTO DA COVID-19 NAS EXPORTAÇÕES DAS PRINCIPAIS COMMODITIES BRASILEIRAS'}

José Aroudo Mota²

\section{SINOPSE}

Diante das incertezas e oscilaçóes no mercado de commodities até 2019, surgiu, a partir de fevereiro de 2020, um novo ator de compressão do comércio internacional: a Covid-19 e seus impactos nas economias globais. Por um lado, alguns dos impactos negativos da pandemia da Covid-19 no produto interno bruto (PIB) dos países que têm laços comerciais com o Brasil já são mensuráveis. Por outro lado, o comércio exterior brasileiro tem demonstrado resiliência, especialmente o setor extrativo mineral e as commodities agrícolas. Este artigo analisa o comportamento do comércio exterior brasileiro no período de 2019 e 2020, enfatizando as principais commodities negociadas no mercado internacional.

Palavras-chave: comércio exterior; balança comercial; setor extrativo mineral; commodities agrícolas.

\section{INTRODUÇÃO}

A pandemia da Covid-19 produziu desaceleração econômica em nível global numa magnitude sem precedentes na história recente. A fim de minimizar esses impactos, os governos injetaram em suas economias um montante significativo de recursos financeiros em 2020, de modo a amortecer em parte o choque da pandemia e viabilizar uma retomada mais rápida da atividade produtiva.

Por seu turno, o Brasil continuou em busca da expansão de negócios, mesmo com as adversidades internacionais decorrentes da pandemia. Neste cenário, os negócios com as commodities minerais destacaram-se, especialmente pela resiliência da economia chinesa ao longo do ano, que manteve elevada sua demanda por insumos minerais e ampliou os seus negócios com o Brasil.

O objetivo deste artigo é avaliar os impactos e as perspectivas da crise gerada pela pandemia sobre as exportaçóes brasileiras de commodities minerais. Para tanto, a análise se concentra na recuperação econômica da China ao longo de 2020, uma vez que este constitui o principal mercado para os produtos minerais brasileiros, bem como na avaliação da retomada das economias centrais, em especial a dos Estados Unidos, após a definição da disputa presidencial em novembro.

\section{MATERIAL DA PESQUISA}

Os dados de comércio exterior do Brasil são catalogados e administrados pelo Ministério da Economia (na Secretaria de Comércio Exterior) e divulgados on-line com a tempestividade que o tema exige. Deste modo, as contas do setor extrativo, assim como as commodities agrícolas foram agrupadas e contabilizadas conforme descritas na tabela 1 .

1. DOI: http://dx.doi.org/10.38116/radar65art5

2. Pesquisador do Subprograma de Pesquisa para o Desenvolvimento Nacional (PNPD) na Diretoria de Estudos e Políticas Setoriais de Inovação e Infraestrutura (Diset) do Ipea. E-mail: <jamota2014@gmail.com>. 


\section{RESULTADOS}

Mesmo diante do retrocesso econômico que desestruturou a economia internacional em decorrência da Covid-19, o faturamento do Brasil com as exportações, ${ }^{3}$ no total de US\$209.878,4 milhóes (tabela 1), apresentou uma queda de 6,9\% em 2020 em relação a 2019; as importaçóes, no montante de US\$ 158.937,3 milhóes, caíram $10,4 \%$ no mesmo período.

Em 2020, os principais destinos das exportaçôes brasileiras foram: em primeiro lugar, a China, com total exportado de US\$ 67,8 bilhóes, correspondendo a 32,3\% das exportaçóes, e variação positiva de 7\% em relação a 2019, enquanto as importaçóes totalizaram US\$34,0 bilhóes, correspondendo a 23,3\% do total importado, e retração de 3,5\% em relação a 2019; em seguida, os Estados Unidos, com total exportado de US\$21,5 bilhões, correspondendo a 10,2\% das exportaçóes, e variação negativa de $27,7 \%$ em relação a 2019 , enquanto as importaçóes totalizaram US\$24,1 bilhões, correspondendo a 16,5\% do total importado, e retração de 19,8\% em relação a 2019. A pauta exportadora do Brasil em 2020 foi concentrada nos estados de Sáo Paulo (com participação de 20,4\%), Minas Gerais (com 12,6\%), Rio de Janeiro (com 11,0\%) e Pará (com 9,9\%), os quais foram responsáveis por $53,9 \%$ do total exportado.

Diante da conjuntura econômica nacional, decorrente dos efeitos de externalidades negativas gerados pela Covid-19, o impacto nas perdas das exportaçóes de commodities minerais foi sendo minimizado a partir da recuperação da economia internacional. O mês de março de 2020 foi marcado por um descompasso internacional caracterizado pelo início do retorno da atividade econômica na China, por um lado, e pelo agravamento da pandemia nos demais países, por outro lado. No Brasil, várias medidas de distanciamento social com o objetivo de conter a contaminação e preparar o sistema de saúde nacional para tratar os doentes foram iniciadas em todo o país. A partir de então, ao passo que a atividade econômica doméstica sofria com as medidas de contenção da pandemia, as exportaçóes brasileiras ganhavam impulso em decorrência da demanda proporcionada por grandes investimentos em infraestrutura realizados pela China. Por isso, chama atenção a declaraçáo do professor George Yip de que:

A China está se recuperando mais rapidamente do coronavírus do que o resto do mundo, o que significa que sua economia avançará e fortalecerá sua posição nas negociaçóes comerciais com os Estados Unidos. Enquanto isso, a queda no valor de mercado das empresas britânicas tornará mais fácil para as empresas chinesas, que são menos dependentes do mercado de açôes, fazer a aquisição de empresas ocidentais (WILSON, 2020, tradução nossa).

Os ganhos e as perdas aparentes decorrentes da pandemia da Covid-19 estão demonstrados na tabela 1. Ao contrário da tendência geral da pauta exportadora brasileira, as commodities do setor extrativo mineral aumentaram o seu faturamento em 14,5\% em 2020 contra 2019, correspondendo a um ganho de quase US\$ 4,3 bilhóes e pouco mais de 1,8 milhão de toneladas exportadas a mais.

O minério de ferro ${ }^{4}$ e seus concentrados se destacam, mesmo com uma perda aparente de comércio de 245,0 mil toneladas, mas com um ganho substancial no total exportado de pouco mais de US\$ 3 bilhóes, resultado influenciado pela alta nos preços por tonelada. Os principais compradores foram a China, com $71,8 \%$ do total exportado, e a Malásia, num distante segundo lugar, com 6,6\% de participação.

O ouro não monetário, com aumento de 34,0\% nas exportaçóes no mesmo período, apresentou um ganho de US\$ 1,2 bilhão, correspondendo a 5,0 toneladas adicionais em 2020. Seus principais compradores foram o Canadá (com 38,2\% de participação), a Suíça (com 21,0\%), o Reino Unido (com 13,1\%), os Emirados Árabes (com 7,8\%) e a Itália (com 6,1\%, aproximadamente). O preço médio de exportação do ouro aumentou 13,2\% em 2020 com base em 2019, sendo negociado a US\$ 44,4 mil FOB $/ \mathrm{kg}$.

3. Todos os valores estão expressos em dólares americanos.

4. 0 minério de ferro representou, em 2020, 12,3\% das exportações do Brasil; e ocupou o segundo lugar no ranking das exportações totais e o primeiro no ranking da indústria extrativa mineral. Os preços de sua exportação em dólares free on board por quilo (US\$ FOB/kg) aumentaram 33,3\% em 2020 com base em 2019. 
O grupo da soja e seus derivados, por sua vez, obteve, em 2020, um aumento de 9,5\% em relação a 2019, equivalente a um ganho de US\$ 2,5 bilhóes e de 8,9 milhóes de toneladas no volume exportado no mesmo período. Os diversos tipos de carne também obtiveram ganhos em suas exportaçóes no mesmo período, atingindo US\$ 550,8 milhóes e 352,2 mil toneladas no volume exportado. Entretanto, o milho apresentou um desempenho negativo, com US\$ 1,4 bilhão de perda de exportação em relação a 2019, referentes a 8,3 milhóes de toneladas.

Este grupo de produtos (composto por commodities da indústria extrativa mineral, óleos brutos de petróleo, soja e derivados, diversos tipos de carne e milho) respondeu por 49,6\% das exportaçóes de 2020 e 45,6\% das de 2019; no conjunto, apresentou um ganho, em 2020, no valor de US\$1,3 bilhão.

TABELA 1

Ganhos e perdas nas exportações brasileiras de commodities (2019 e 2020)

\begin{tabular}{|c|c|c|c|c|}
\hline \multirow{2}{*}{ Principais produtos exportados } & \multicolumn{2}{|c|}{ Exportações (US\$ milhões) } & \multicolumn{2}{|c|}{ Ganho ou perda } \\
\hline & 2019 & 2020 & US\$ milhões & Toneladas \\
\hline 1. Minério de ferro e seus concentrados & $22.680,9$ & $25.780,5$ & $3.099,6$ & $-245,0 \mathrm{mil}$ \\
\hline 2. Minério de cobre e seus concentrados & $2.325,7$ & $2.408,9$ & 83,2 & $-13,3 \mathrm{mil}$ \\
\hline 3. Ouro, uso não monetário & $3.658,4$ & $4.903,4$ & $1.245,0$ & 5,043 \\
\hline 4. Minério de manganês & 490,1 & 346,6 & $-143,5$ & $-712,9 \mathrm{mil}$ \\
\hline 5. Minério de alumínio & 258,3 & 169,5 & $-88,8$ & $2.580,0 \mathrm{mil}$ \\
\hline 6. Demais minérios & 87,2 & 178,8 & 91,6 & $220,3 \mathrm{mil}$ \\
\hline 7. Indústria extrativa mineral $(1+\ldots+6)$ & $29.500,6$ & $33.787,7$ & $4.287,1$ & $1.829,1 \mathrm{mil}$ \\
\hline 8. Óleos brutos de petróleo & $24.199,5$ & $19.613,8$ & $-4.585,7$ & $-9.928,7 \mathrm{mil}$ \\
\hline 9. Indústria extrativa $(7+8)$ & $53.700,1$ & $53.401,5$ & $-298,6$ & $\ldots$ \\
\hline 10. Soja e seus derivados 1 & $26.773,5$ & $29.327,6$ & $2.554,1$ & $8.968,9 \mathrm{mil}$ \\
\hline 11. Diversos tipos de carnes2 & $15.015,3$ & $15.566,1$ & 550,8 & $352,2 \mathrm{mil}$ \\
\hline 12. Milho & $7.212,2$ & $5.786,1$ & $-1.426,1$ & $-8.323,7 \mathrm{mil}$ \\
\hline Subtotal $(9+10+11+12)$ & $102.701,1$ & $104.081,3$ & $1.380,2$ & $\ldots$ \\
\hline Demais produtos & $122.682,4$ & $105.797,1$ & $-16.885,3$ & $\ldots$ \\
\hline Total & $225.383,5$ & $209.878,4$ & $-15.505,1$ & \\
\hline
\end{tabular}

Fonte: Comex Stat (estatísticas de comércio exterior brasileiro). Disponível em <http://comexstat.mdic.gov.br/pt/home>. Acesso em: 14 fev. 2021.

Elaboração do autor.

Notas: ' Soja mesmo triturada + farelo e resíduos da extração de óleo de soja.

${ }^{2} \mathrm{~A}$ conta inclui carne de bovino, equino, caprino, frango, pato, ganso e peru congelada, fresca ou refrigerada (as carnes de frango, pato, ganso e peru incluem os miúdos) + carnes salgadas incluídas as de frango + tripas e buchos de animais, frescos, salgados ou secos.

\section{CONSIDERAÇÕES FINAIS}

Os impactos da Covid-19 nas exportaçóes brasileiras foram marginais, quando comparados com as demais economias mundiais, em virtude da forte demanda chinesa. O saldo comercial com a China, em 2020, foi superavitário em US\$ 33,7 bilhóes e a corrente de comércio atingiu US\$101,8 bilhóes; entretanto, com os Estados Unidos, o saldo de comércio apresentou um deficit de US\$2,6 bilhóes e uma corrente de comércio de US\$ 45,6 bilhóes.

No final de fevereiro de 2021, após amplo esforço bipartidário, o Congresso dos Estados Unidos aprovou um pacote de estímulos de US\$ 1,9 trilhão, destinado a mitigar os efeitos econômicos da pandemia da Covid-19 e acelerar a retomada do emprego e da produção industrial. Embora seus efeitos ainda estejam por ser sentidos nos próximos meses, o anúncio do pacote já precipitou uma melhoria nas expectativas quanto ao desempenho da economia global. Uma vez que a China é bastante impactada pelo desempenho da economia americana, essa injeção significativa de recursos também deve acelerar a recuperaçáo econômica do país asiático, com impactos indiretos positivos para a exportação de commodities minerais do Brasil. 
Certamente, dois pontos devem chamar atenção dos gestores públicos brasileiros. $\mathrm{O}$ primeiro se refere à elevada dependência de produtos primários em nossa pauta exportadora; e o segundo, à excessiva concentração em poucos parceiros comerciais. $\mathrm{O}$ momento é de cautela, pois o país precisa, primeiro, sair da pandemia para permitir um crescimento econômico duradouro e, num segundo momento, definir políticas públicas de inovação e tecnologia para agregar valor aos produtos exportados pelo Brasil.

\section{REFERÊNCIA}

WILSON, J. The economic impact of coronavirus: analysis from Imperial experts. Imperial College London News, 13 May 2020. Disponível em: <https://bit.ly/3tyP5zM>. Acesso em: 16 maio 2020.

\section{BIBLIOGRAFIA COMPLEMENTAR}

KRUGMAN, P. Republicans, businesspeople, and other bad economists. The New York Times, New York, 25 Aug. 2020. THE ECONOMIST. Economic \& financial indicators. The Economist, London, v. 435, n. 9194, p. 80, 16 May 2020. 


\section{CONTRIBUIÇÃO DO SETOR MINERAL NO PRODUTO INTERNO BRUTO BRASILEIRO ${ }^{1,2}$}

Rodrigo César de Vasconcelos dos Santos 3

\section{SINOPSE}

O setor mineral (SM) brasileiro é um segmento importante para a economia nacional em virtude de suas vastas reservas e bom posicionamento no comércio mundial de commodities minerais. Conhecendo o desdobramento do SM juntamente com uma demanda do Ministério de Minas e Energia, este trabalho tem o objetivo de mensurar o valor adicionado bruto (VAB) para o SM brasileiro e interpretá-lo como variável proxy do próprio produto interno bruto (PIB) para o período que vai de 2000 até 2018, bem como estimar o VAB do SM para 2019 e 2020 por meio de modelos econométricos. O trabalho é todo realizado a partir dos dados da Tabela de Recursos e Usos (TRU) do Sistema de Contas Nacionais (SCN), publicado pelo Instituto Brasileiro de Geografia e Estatística (IBGE). Para 2019 e 2020, a estimativa da contribuição do SM brasileiro no PIB é respectivamente de 3,190\% e 3,182\%.

Palavras-chave: mineração; PIB; transformação mineral; VAB.

\section{INTRODUÇÃO}

O setor mineral (SM) brasileiro é um segmento importante para a economia nacional em virtude de o Brasil possuir vastas reservas e estar bem-posicionado no comércio mundial de commodities minerais. Portanto, é imprescindível quantificar e estimar com maior precisão o produto interno bruto (PIB) do SM e seus encadeamentos. Contudo, algumas dificuldades metodológicas surgem na tentativa de explicar o SM, por dois motivos básicos: primeiramente, a seção B da Classificação Nacional de Atividades Econômicas (CNAE), que trata das indústrias extrativas, inclui a exploração de petróleo e gás; em segundo lugar, na seção C da CNAE, que trata das indústrias de transformação, estão alguns segmentos que constituem o SM brasileiro e é importante incluí-los no PIB do SM.

Até o momento, não se sabe qual é a contribuição do SM no PIB brasileiro, o que exige, portanto, uma investigação dos setores que compóe o SM, que seriam a indústria extrativa mineral (IEM) e indústria da transformação mineral (ITM).

Este trabalho tem o objetivo de mensurar o valor adicionado bruto (VAB) para o SM brasileiro e interpretálo como variável proxy do próprio $\mathrm{PIB}^{4}$ do SM (entendendo-se este como a riqueza monetária agregada ao PIB corrente) para o período que vai de 2000 até 2018, bem como estimar o VAB do SM para 2019 e 2020 por meio de modelos econométricos.

\footnotetext{
1. DOI: http://dx.doi.org/10.38116/radar65art6

2. 0 autor agradece os comentários e as sugestões dos pesquisadores Daniel Monte Cardoso, Eduardo Vale e José Aroudo Mota. Qualquer erro ou equívoco no texto é de sua inteira responsabilidade.

3. Pesquisador do Subprograma de Pesquisa para o Desenvolvimento Nacional (PNPD) na Diretoria de Estudos e Políticas Setoriais de Inovação e Infraestrutura (Diset) do Ipea.E-mail: <rodrigo.cesar@ipea.gov.br>.

4. Uma variável proxy objetiva substituir uma variável original, a qual é de difícil mensuração ou não existe nas estimativas de dados econômicos, por exemplo. Assim, uma proxy é uma variável de proximidade que pode substituir outra variável, cuja função de proximidade é corrigir ou amenizar o grau de explicação de um fenômeno econômico, social ou ambiental.
} 
O trabalho foi todo realizado a partir dos dados da Tabela de Recursos e Usos (TRU) do Sistema de Contas Nacionais (SCN), publicado pelo Instituto Brasileiro de Geografia e Estatística (IBGE). Até o momento, o SCN possui resultados definitivos apenas até 2018 e para 51 atividades econômicas. Obviamente, apenas as atividades relacionadas ao SM foram utilizadas nessas estimativas.

De acordo com a classificação de atividades do SCN, é possível definir a IEM como o conjunto das atividades de extração de carvão mineral e de minerais não metálicos, extração de minério de ferro, inclusive beneficiamentos e aglomeração, extração de minerais metálicos não ferrosos, inclusive beneficiamentos, com exceção da atividade de extração de petróleo e gás natural.

Em relação à ITM, sua definição engloba cinco setores da indústria de transformação: fabricação de cimento e outros produtos de minerais não metálicos; fabricação de aços e derivados; produção de tintas, vernizes, esmaltes e lacas; metalurgia de metais não ferrosos; e fabricação de produtos de metal - o que inclui produtos como: estruturas metálicas, obras de caldeiraria pesada, fabricação de tanques, reservatórios metálicos, forjaria, estamparia, metalurgia em pó, serviços de tratamentos de metais, fabricação de artigos de cutelaria, serralheria, ferramentas, equipamento bélico pesado, armas de fogo e muniçôes, mas exclui a fabricação de máquinas e equipamentos.

\section{RESULTADOS - MENSURAÇÃO DO VAB DO SM ENTRE 2000 E 2018 E ESTIMAÇÃO PARA 2019 E 2020}

O gráfico 1 mostra os valores a preços correntes do SM (IEM + ITM) entre 2000 e 2018.

\section{GRÁFICO 1}

Agregação das contas do SM brasileiro (2000-2018)

(Em R\$ milhões correntes)

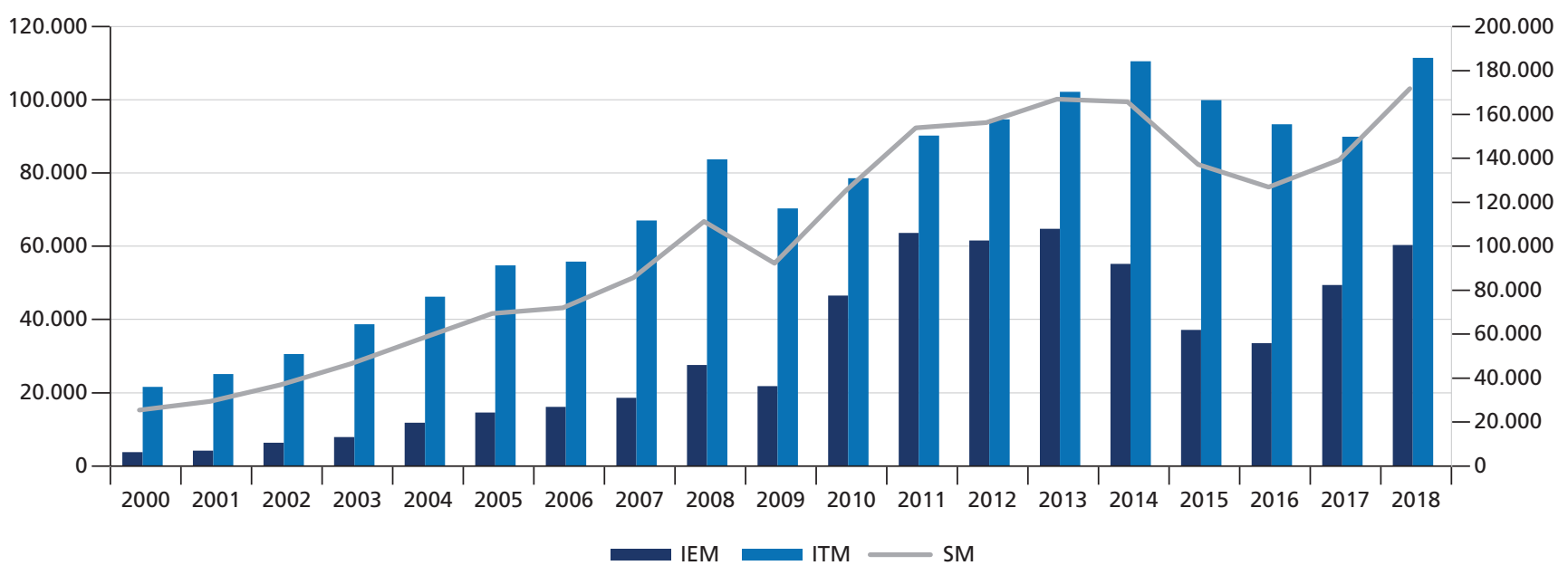

Elaboração do autor.

A partir da definição da IEM, foi constatado um aumento do VAB entre 2000 e 2008, depois uma leve queda em 2009 e, na sequência, um aumento até 2013. Quedas foram percebidas de 2013 a 2016, enquanto os anos de 2017 e 2018 foram de crescimento. Apesar das oscilaçóes, a IEM apresentou trajetória crescente ao longo da série histórica, em consonância com os preços das commodities minerais, que mantiveram trajetória crescente até 2013. Em valores correntes, foi observada uma queda do VAB da IEM até 2016, quando se inicia um breve movimento de valorização das commodities minerais. 
De maneira mais específica, vale notar que, durante o período analisado, o VAB da atividade de extração de minério de ferro foi superior ao de outras da indústria extrativa, mostrando a representatividade deste minério na composição do VAB do SM. A partir de 2002, o minério de ferro ganha ainda mais destaque, tendo um crescimento até 2008, apresentando leve queda em 2009, em decorrência da crise financeira internacional de 2008. Já a partir de 2010, ocorre elevação na produção até 2014, e esse ciclo de alta é novamente interrompido pela crise de 2015 e 2016; já em 2017, inicia-se uma nova retomada. No que se refere aos outros itens da indústria extrativa, percebeu-se uma ligeira alta no VAB até 2009. De 2010 até 2018, tem-se pouca oscilação, com um $\mathrm{VAB}$ a preços correntes em torno de $\mathrm{R} \$ 12$ bilhóes.

O VAB da ITM apresentou uma trajetória crescente até 2008. De 2008 para 2009, houve uma queda influenciada pela recessão econômica mundial e, na sequência, um crescimento até 2014, quando novamente ocorreu uma inflexão na trajetória de crescimento econômico brasileiro. O segmento metalúrgico foi, ao longo da série histórica, o principal beneficiado pelo crescimento brasileiro, seguido de fabricação de produtos de minerais não metálicos e fabricação de produtos de metal.

O VAB do SM teve crescimento de 2000 até 2008, tendo uma queda em 2009, causada pela recessão econômica mundial. Voltou a crescer até 2013 e estabilizou-se em 2014, tendo novamente uma leve queda. O VAB do SM atingiu seu ápice em termos nominais em 2018, cujo valor corrente foi em torno de R\$ 168 bilhóes. Também houve queda do VAB em 2014, 2015 e 2016. Os demais anos foram de crescimento, sendo o maior crescimento constatado em 2010, pós-recessão.

No que se refere à porcentagem do SM no PIB brasileiro, em 2000, a IEM contribuía com apenas 0,366\% no PIB brasileiro. Porém, a IEM teve crescimento representativo até 2008, quando superou a marca de $1 \%$ na contribuição do PIB nacional. Durante a recessão econômica de 2009, houve uma queda da participação da IEM no PIB, mas logo em seguida ocorreu um forte crescimento entre 2010 e 2017, sendo seu ápice de participação no PIB nacional em 2011, no qual a sua contribuição foi de 1,710\%. A estimativa da participação da IEM no PIB para 2019 e 2020 foi de 1,257\% e 1,293\%, respectivamente.

A ITM sempre teve uma contribuição mais representativa no PIB brasileiro do que a IEM. Praticamente a mesma tendência de aumento e queda observada na IEM também se deu na ITM, visto que ambas estão intimamente interligadas. Portanto, percebeu-se um crescimento na contribuição da ITM no PIB brasileiro de 2000 a 2008, ano em que atingiu sua maior contribuição, de 3,190\%. Uma queda em 2009 foi observada e pode ser explicada por conta da recessão econômica mundial. A estimativa da participação da ITM no PIB foi de 1,933\% para 2019, e apresentou uma leve queda, indo para 1,889\% em 2020.

Somando os VABs das IEMs e das ITMs, obtém-se o VAB do SM, o que pode ser interpretado como uma proxy do PIB da economia mineral brasileira, incluindo, como já observado, todos os segmentos da cadeia produtiva mineral da indústria de transformação. A participação do SM no PIB brasileiro foi crescente até 2008, ano com contribuição mais elevada, de 4,239\%. A estimativa da participação da SM no PIB para 2019 e 2020 foi de $3,190 \%$ e $3,182 \%$ respectivamente.

\section{CONSIDERAÇÕES FINAIS}

Este artigo iniciou o esforço de mensurar a participação do SM no PIB brasileiro utilizando o VAB como variável proxy. Compreendeu-se o SM como o complexo econômico que gira em torno da cadeia produtiva da mineração, englobando as próprias atividades de extração mineral (definidas como IEM) e também um conjunto de atividades de transformação industrial diretamente conectadas à extração (definidas como ITM). Esse esforço esteve centrado nas pesquisas oficiais do IBGE, mais especificamente nas Contas Nacionais - cuja publicação remete diretamente ao cálculo do PIB da economia brasileira e de seus setores. 
A partir dos dados obtidos pelas Contas Nacionais foram estimados os valores absolutos e relativos do PIB da economia mineral, apresentando-os separadamente em IEM, ITM e SM (como soma das IEM e das ITM). Assim, em 2019, a IEM e a ITM corresponderam, nesta ordem, a 1,257\% e 1,933\% do PIB brasileiro, enquanto, para 2020, esses valores foram, respectivamente, de 1,293\% e 1,889\%. Portanto, com base no modelo proposto e na proxy do VAB da indústria para 2019 e 2020, a estimativa do SM brasileiro no PIB é de 3,190\% e 3,182\%, respectivamente.

Vale ressaltar que a apresentação dos resultados separadamente é importante para que se diferencie cada um dos segmentos na cadeia produtiva da mineração, mesmo que se queira olhar pela ótica do SM.

\section{REFERÊNCIAS}

IBGE - INSTITUTO BRASILEIRO DE GEOGRAFIA E ESTATÍSTICA. Empresa. Pesquisa Industrial, Rio de Janeiro, v. 37, n. 1, p. 1-46, 2018a. Disponível em: <https://bit.ly/2R3Atdl>.

. Tabelas completas. Sistema de contas nacionais. Rio de Janeiro, 2018b. Disponível em: <https://bit.ly/3vlB2yd>.

. Sistema de Contas Nacionais - Brasil 2017. Rio de Janeiro: IBGE, 2019. (Notas Técnicas). Disponível em: <https://bit.ly/3gEAqQ4>. 


\title{
IMPACTOS DAS MUDANÇAS NA POLÍTICA NORTE-AMERICANA PARA O SETOR MINERAL BRASILEIRO'
}

\author{
Rodrigo César de Vasconcelos dos Santos ${ }^{2}$ \\ Daniel Monte Cardoso ${ }^{3}$
}

\section{SINOPSE}

Este artigo analisa os possíveis impactos das mudanças na política norte-americana sobre o setor mineral brasileiro. O presidente dos Estados Unidos recém-eleito tem sinalizado sua preferência por uma matriz energética mais limpa, o que poderia beneficiar o Brasil - que possui uma das matrizes energéticas mais limpas do mundo - por possuir consideráveis reservas de minerais primordiais para a confecção de baterias e painéis solares, por exemplo.

Palavras-chave: energias renováveis; Estados Unidos da América; floresta amazônica; garimpo; minerais estratégicos.

\section{INTRODUÇÃO}

A ascensão de um novo governo norte-americano em 2020 sinaliza para políticas de preservação ambiental que repercutem no Brasil. Neste sentido, algumas medidas do novo governo se orientam no sentido de redução do desmatamento florestal (sobretudo na Amazônia) e de maior preservação das regiôes que abrigam os povos originários brasileiros. Além disso, o presidente recém-eleito tem sinalizado para a retomada dos acordos climáticos, a diminuição das emissóes de carbono e os incentivos a fontes de energia renováveis, o que deverá impactar o uso de novos insumos industriais, tais quais lítio, cobalto, níquel e minerais terras raras na indústria de transformação. Assim, este artigo visa mostrar alguns dos possíveis impactos da eleição de Joe Biden sobre o setor mineral no Brasil, considerando seus aspectos ambientais e econômicos.

\section{ENERGIAS RENOVÁVEIS E MINERAIS ESTRATÉGICOS}

O presidente norte-americano recém-eleito, Joe Biden, prometeu um plano bastante ambicioso de mudança da matriz energética dos Estados Unidos para a próxima década, em linha com as expectativas do eleitorado democrata que lhe concedeu a maior votação da história do país em 2020. Seu objetivo é incentivar as fontes energéticas renováveis e diminuir drasticamente o consumo de combustíveis fósseis já a partir dos próximos anos. Nesse sentido, Biden prometeu promover ainda mais a indústria de carros elétricos nos Estados Unidos, o que inclui desde a fabricação de veículos até a construção de estações de recarga, além de incentivar a produção de energias eólica e solar. Se concretizadas, essas políticas aumentarão a demanda de minérios como lítio, grafita e cobalto.

Sob essa perspectiva, o Brasil pode ser beneficiado, uma vez que diversas empresas mineradoras estão fazendo estudos para prospectar o lítio no país. Além do lítio, o Brasil pode reduzir sua dependência de outros minerais, 
tais como grafita, cobalto e minerais terras raras, pois é concreta a possibilidade de se ampliar a produção destes minérios. Futuramente, o país poderia ainda conquistar novos mercados e ampliar o market share da mineração brasileira no mundo.

Nove países, incluindo o Brasil, aderiram à iniciativa em busca de reservas de minérios utilizados na fabricação de veículos elétricos, parte de um esforço para reduzir a dependência mundial dos materiais de alta tecnologia chineses (Reuters, 2019). Os Estados Unidos auxiliarão esses países a prospectar e extrair o conjunto de minerais, bem como aconselhar sobre estruturas de gestão e governança para garantir os investimentos internacionais. Isso ocorre pela preocupação americana com sua dependência das importaçóes de minerais depois que Pequim sugeriu usá-los como alavanca na guerra comercial, o que poderia interromper a fabricação de uma ampla gama de bens de consumo, industriais e militares, incluindo telefones celulares, veículos elétricos, baterias e avióes de combate. Sendo assim, o Departamento de Defesa americano está em busca de minerais estratégicos, incluindo terras raras, em todo o mundo.

O Ministério de Minas e Energia (MME) do Brasil e o Departamento de Estado dos Estados Unidos da América anunciaram o estabelecimento do grupo de trabalho Brasil-Estados Unidos sobre minerais estratégicos, a fim de avançar na cooperação bilateral em minerais essenciais para a segurança, a prosperidade e o desenvolvimento sustentável de ambos os países (MME se reúne..., 2020). O grupo de trabalho objetiva apoiar o avanço do relacionamento diplomático e a cooperação técnica bilateral em minerais estratégicos, inclusive melhorando a segurança no abastecimento dessas substâncias nos dois países, promovendo mineração e cadeias de produção economicamente viáveis, estimulando investimentos, promovendo inovaçáo tecnológica e aumentando a interconectividade bilateral ao longo das cadeias de suprimento de minerais estratégicos.

Estudo realizado pelo Banco Mundial (Arrobas et al., 2017) mostra que é necessário aumentar a oferta de bauxita, alumínio, cobalto, cobre, zinco, chumbo, lítio, níquel, metais do grupo platina e terras raras para que se possa atender as necessidades tecnológicas da transição de uma economia baseada em combustíveis fósseis para uma baseada em energia limpa (Ibram, 2018).

Em fevereiro de 2021, o setor de energia solar brasileiro possuía mais de 7,7 GW de capacidade operacional. ${ }^{4}$ Uma estimativa governamental indica, porém, que a energia solar distribuída no Brasil até 2030 será de 22 GW. Conforme a entidade, de janeiro a maio de 2020, o setor de energia solar criou mais de 37 mil empregos no país, mesmo com a pandemia. Somente em maio, foram gerados 7,2 mil postos de trabalho, trazendo R $\$ 1$ bilhão em novos investimentos e uma arrecadação de mais de $\mathrm{R} \$$ 424,5 milhóes aos cofres públicos. Uma das líderes em energia solar, a brasileira Aldo é a empresa que mais cresce no segmento de energia solar no país; suas placas solares são constituídas por uma ampla gama de metais e demandam uma grande quantidade de minérios, tais como o zinco e o silício. Não é diferente quando se fala em energia eólica, pois as turbinas, torres e pás utilizadas na geração de energia também demandam grande quantidade de minérios para sua confecção.

\section{RELAÇÕES COMERCIAIS}

Ainda é cedo para se avaliarem os impactos da mudança política nos Estados Unidos sobre as relaçóes comerciais com o Brasil. Contudo, pode-se inferir que os estímulos econômicos às matrizes energéticas renováveis impactariam negativamente o segmento de carvão mineral, que perderia participação em termos de produção e comércio, e estimulariam a produção de bens de maior conteúdo tecnológico, o que aumentaria a demanda por minerais como lítio, níquel, cobalto e minerais terras raras.

4. De acordo com o panorama da energia solar fotovoltaica no Brasil e no mundo, divulgado mensalmente pela Associação Brasileira de Energia Solar Fotovoltaica (Absolar), de 2 de fevereiro de 2021. Disponível em: <https://www.absolar.org.br/mercado/infografico/>. Acesso em: 13 fev. 2021. 
A difícil relação dos Estados Unidos com a China gera incertezas acerca da trajetória do setor mineral no contexto global, tanto no que se refere à organização das cadeias de suprimento quanto em relação à exploração de bens minerais de vanguarda, como os "terras raras", cujos depósitos estão majoritariamente concentrados na China. Acredita-se que a indústria mineral americana tenderá a diminuir a dependência da China procurando por fontes minerais mais próximas. Ademais, o movimento protecionista em curso pode favorecer pequenos produtores em detrimento dos grandes e impactar negativamente o fluxo de comércio global de commodities minerais (Cholteeva, 2021).

No que concerne ao setor mineral brasileiro, suas exportaçóes sáo direcionadas predominantemente para a China, principalmente os insumos de metais básicos, como é o caso do minério de ferro. Neste sentido, a evolução das exportações brasileiras dependerá menos das açôes do governo norte-americano e mais da tração da economia chinesa nos próximos anos. Contudo, se o governo dos Estados Unidos efetivamente promover uma transição energética de matrizes renováveis, será fundamental que o Brasil promova investimentos em pesquisa e prospecção de bens e insumos minerais utilizados nas novas tecnologias que surgirão no futuro.

\section{MUDANÇAS CLIMÁTICAS E PROTEÇÃO DA FLORESTA AMAZÔNICA}

Uma das primeiras atitudes do governo Biden foi a retomada do Acordo de Paris, pelo qual os países se comprometem com metas de redução das emissóes de carbono na atmosfera, no intuito de frear o aquecimento global. O presidente norte-americano busca cooperar em questóes como a mudança climática, o que deverá envolver o Brasil, tendo em vista a importância da preservação da Amazônia para a regulação climática mundial.

O crescimento do desmatamento florestal amazônico está intimamente ligado às práticas de devastação não legalizadas, no intuito de abrir espaço para a exploração agropecuária, além da extração ilegal de madeira e de alguns segmentos da indústria extrativa mineral.

Souza-Filho et al. (2021) estimaram a área terrestre afetada pela mineração em áreas protegidas e não protegidas na região amazônica. Constataram que a mineração ocupa $1.110 \mathrm{~km}^{2}$ da Amazônia, sendo $65 \%$ pertencentes ao garimpo ilegal e os outros 35\% relacionados à mineração em escala industrial. Na região, 47\% da área total de mineração estava localizada em áreas protegidas, onde a extração era dominada pelo garimpo. A exploração de ouro foi responsável por $58 \%$ da área total, seguida por alumínio (15\%), estanho (13\%) e ferro (8\%). Os autores concluíram que a mineração industrial de ferro apresentou os menores impactos em áreas de mineração com maior extração mineral comercializada, enquanto a produção de ouro por meio do garimpo contrariou as metas de conservação ambiental.

Neste sentido, mecanismos regulatórios devem ser implantados pela Agência Nacional de Mineração (ANM) juntamente com o MME visando desenvolver a extração mineral de modo a evitar os impactos da mineração de ouro em pequena escala e sua infraestrutura náo planejada, que pode ser considerada a nova força motriz do desmatamento da Amazônia, como constatado por Souza-Filho et al. (2021). No que se refere à política e às parcerias internacionais, a França e a Alemanha têm cobrado maior respeito à autonomia dos povos indígenas para fechar acordos com o Mercosul. Portanto, é importante que o Brasil reveja algumas práticas ambientais predatórias, inclusive no setor mineral, evitando sofrer prejuízos econômicos e comerciais no futuro.

De acordo com o Instituto Socioambiental (ISA), 3.773 requerimentos minerários afetam 31 terras indígenas e 17 unidades de conservação, que possuem 71 registros de povos indígenas isolados em seu perímetro (Moreira e Oviedo, 2020). Desses, são 7 registros confirmados, 17 em estudo e outros 47 com informação. Ainda que sejam requeridas ao menos 43 substâncias, somente o ouro concentra em torno de $58 \%$ dos processos. Cabe frisar que a imensa maioria desses requerimentos (3.053) ainda se destina para pesquisa, uma fase pré-exploratória dos recursos. Não obstante, a expansão não planejada da atividade minerária poderá trazer diversos impactos negativos para as populações indígenas nas próximas décadas. 


\section{CONSIDERAÇÕES FINAIS}

O novo governo norte-americano promete trazer mudanças nos esforços globais de preservação ambiental (metas de redução da emissão de carbono e do desmatamento, e incentivos aos acordos climáticos vigentes), o que poderá reduzir progressivamente a utilização de combustíveis fósseis, a mudança da matriz energética norte-americana e a utilizaçáo de novos insumos minerais relacionados à indústria de transformação de alta tecnologia.

Em linha com países desenvolvidos como a França, a Alemanha, o Canadá e outros membros da União Europeia, as novas orientaçôes do governo norte-americano deverão pressionar o Brasil pela redução do desmatamento florestal, por menores impactos sobre as terras protegidas e por maiores incentivos à transição energética para matrizes renováveis. Neste sentido, o Brasil poderá se beneficiar fortemente dos novos insumos que deverão ser explorados nos próximos anos, sobretudo aqueles ligados à indústria de alta tecnologia, como lítio, grafita, cobalto, níquel e terras raras.

\section{REFERÊNCIAS}

ARROBAS, D. P. et al. The growing role of minerals and metals for a low carbon future. Washington: World Bank; EGPS, June 2017. (Working Paper, n. 117581). Disponível em: <https://bit.ly/2Q44TvV>.

CHOLTEEVA, Y. What will the next US administration mean for mining? Mine Magazine, London, v. 100, Jan. 2021. Disponível em: <https://bit.ly/3xhay2P>. Acesso em: 13 fev. 2021.

IBRAM - INSTITUTO BRASILEIRO DE MINERAÇÃO. Eleiçóes 2018: políticas públicas para indústria mineral. Brasília: Ibram, 2018. 105 p.

MME SE REÚNE com o Escritório de Recursos Energéticos do Departamento de Estado dos EUA para dialogar sobre oportunidades no setor. MME Notícias, Brasília, 10 nov. 2020. Disponível em: <https://bit.ly/3n0BNK4>. Acesso em: 18 fev. 2021.

MOREIRA, T.; OVIEDO, A. O futuro das terras indígenas com as medidas do PL 191/2020. São Paulo: ISA, 2020. (Nota técnica). Disponível em: <https://bit.ly/3eej5dX>. Acesso em: 15 fev. 2021.

REUTERS. Nine countries join US strategic minerals initiative. Mining Weekly, Johannesburg, 26 Sept. 2019. Disponível em: <https://bit.ly/3ehgPTc>. Acesso em: 18 fev. 2021.

SOUZA-FILHO, P. W. M. et al. Land-use intensity of official mineral extraction in the Amazon region: linking economic and spatial data. Land Degrad Dev, p. 1-12, 2021.

\section{SITE CONSULTADO}

OEC - OBSERVATORY OF ECONOMIC COMPLEXITY. Disponível em: <https://oec.world/en/profile/country/ bra>. Acesso em: 15 fev. 2021. 

Ipea - Instituto de Pesquisa Econômica Aplicada

\section{EDITORIAL}

\section{Chefe do Editorial}

Reginaldo da Silva Domingos

\section{Assistentes da Chefia}

Rafael Augusto Ferreira Cardoso

Samuel Elias de Souza

\section{Supervisão}

Camilla de Miranda Mariath Gomes

Everson da Silva Moura

\section{Editoração}

Aeromilson Trajano de Mesquita

Anderson Silva Reis

Cristiano Ferreira de Araújo

Danilo Leite de Macedo Tavares

Jeovah Herculano Szervinsk Junior

Leonardo Hideki Higa

\section{Capa}

Leonardo Hideki Higa

Imagens da Capa

Banco Freepik (freepik.com)

\section{Projeto Gráfico}

Renato Rodrigues Bueno

The manuscripts in languages other than Portuguese published herein have not been proofread.

\section{Livraria Ipea}

SBS - Quadra 1 - Bloco J - Ed. BNDES, Térreo

70076-900 - Brasília - DF

Tel.: (61) 2026-5336

Correio eletrônico: livraria@ipea.gov.br 

Composto em adobe garamond pro 12 (texto) Frutiger 67 bold condensed (títulos, gráficos e tabelas) Rio de Janeiro-RJ 



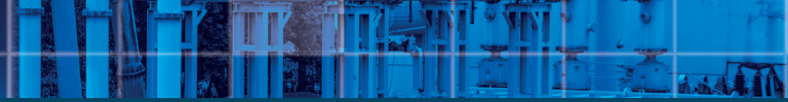

\section{Missão do Ipea}

Aprimorar as políticas públicas essenciais ao desenvolvimento brasileiro por meio da produção e disseminação de conhecimentos e da assessoria ao Estado nas suas decisões estratégicas.
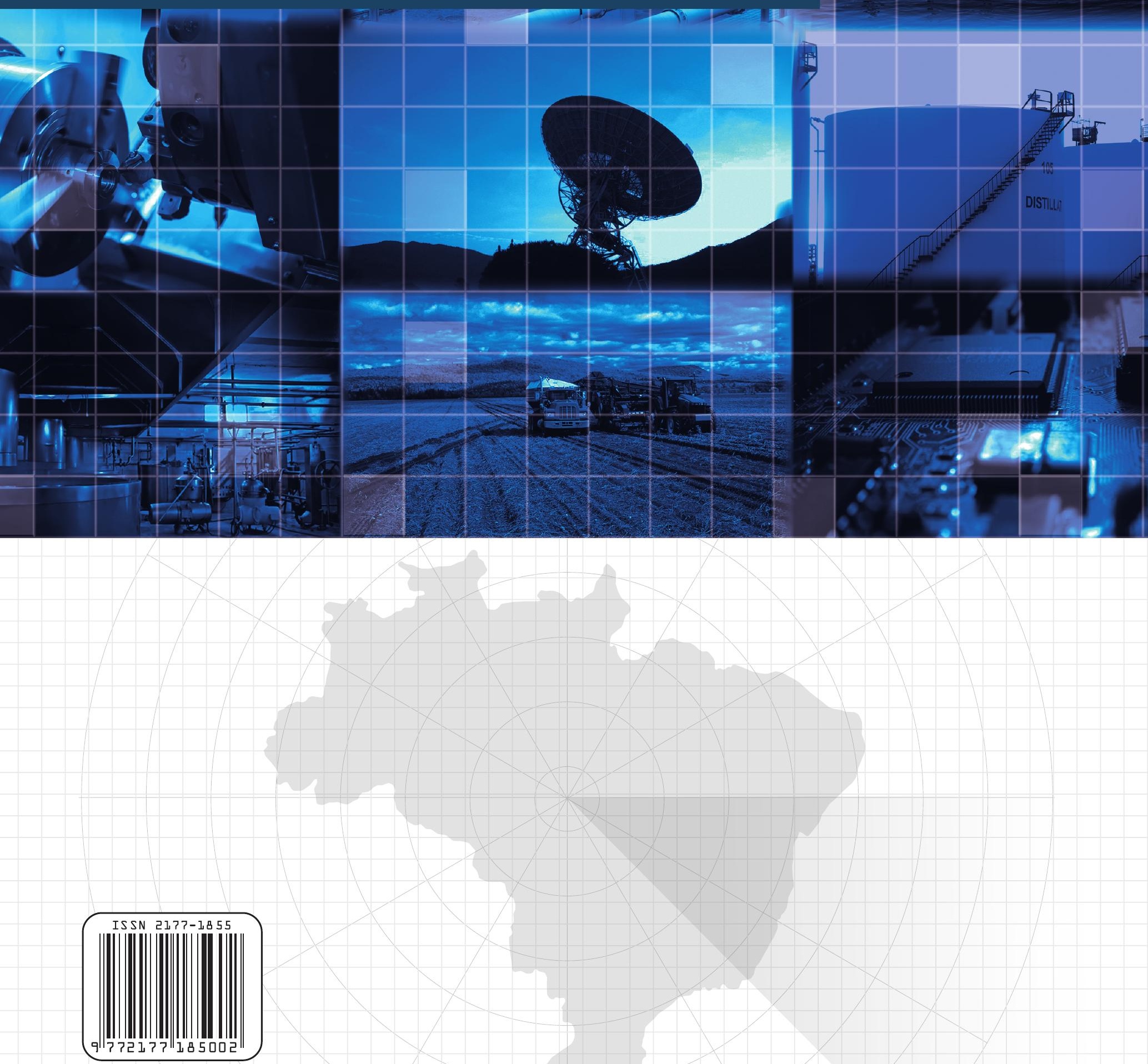